\title{
Synthesis and Antiviral Activities of Novel Purinyl- and Pyrimidinylcarbanucleosides Derived from Indan ${ }^{1}$
}

Nerea Alonso, ${ }^{a}$ Olga Caamaño, ${ }^{a}$ Franco Fernández, ${ }^{a}$ Xerardo García-Mera, ${ }^{\text {a,* }}$ Melvin Morales, ${ }^{\mathrm{a}}$ José Enrique Rodríguez-Borges ${ }^{\mathrm{b}}$ and Eric De Clercq ${ }^{\mathrm{c}}$

${ }^{a}$ Departamento de Química Orgánica, Facultade de Farmacia, Universidade de Santiago de Compostela, E-15782 Santiago de Compostela, Spain. ${ }^{b}$ CIQ, Departamento de Química, Universidade do Porto, Rua do Campo Alegre 687, 4169-007 Porto, Portugal. ${ }^{c}$ Rega Institute for Medical Research, Katholieke Universiteit Leuven, 3000 Leuven, Belgium.

\begin{abstract}
Starting from ( \pm -trans- and $( \pm)$-cis-3-hydroxymethyl-1-indanol, novel 6-substituted purinylcarbanucleoside derivatives of indan $(\mathbf{5}, \mathbf{6}, 9, \mathbf{1 0}, 15$ and 17) were synthesized through a key coupling reaction with 6-chloropurine under Mitsunobu conditions. Suzuki-Miyaura reactions of the protected 6-chloropurine derivative with different arylboronic acids afforded the corresponding 6-arylpurinylcarbanucleoside derivatives. Finally, three new 5halouracilcarbanucleosides $(\mathbf{1 9}, \mathbf{2 0}$ and $\mathbf{2 1})$ were prepared by reaction of uracilcarbanucleoside 18 with different $N$-halosuccinimides. All of the new analogues were evaluated for antiviral activity against a wide variety of viruses.
\end{abstract}

Keywords: Synthesis; Indan carbanucleosides; Mitsunobu reaction; Suzuki-Miyaura reaction; Antiviral activity.

Corresponding author. Fax +34(981)594912; E-mail:qoxgmera@usc.es 


\section{Introduction}

Carbocyclic nucleosides (carbanucleosides) are analogues of nucleosides in which a methylene group has replaced the oxygen atom in the furanose ring. ${ }^{2}$ These analogues show similar biological activities to the parent nucleosides and have higher metabolic and chemical stability against different phosphorylases, hydrolases and cleaving agents. $^{3}$ Of the different carbanucleosides prepared to date, carbovir ${ }^{4}$ has shown significant anti-HIV activity through the selective inhibition of $H I V-1$ reverse transcriptase. Its derivative abacavir ${ }^{5}$ is equally potent but is less toxic, has greater bioavailability and has been approved by the FDA for the treatment of HIV infection. Both of these compounds are cyclopentenyl carbanucleosides and their anti-HIV capacity has stimulated the development of new carbanucleosides in which the carbocycle is a cyclopentane ring.

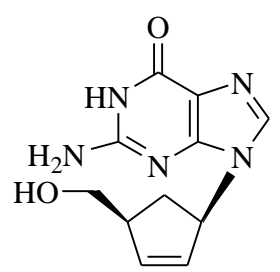

Carbovir

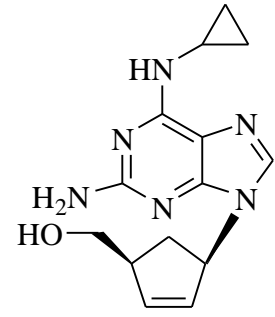

Abacavir

In the last two years our research group has prepared different series' of carbanucleosides derived from indan and these bear purine and pyrimidine bases and are of the type $1^{1}$-homoderivative ${ }^{6}$ and $5^{1}$-nor-1'-homoderivative. ${ }^{7}$ These were synthesised with the aim of increasing the liposolubility of the compounds and to facilitate their access to the central nervous system, a significant reservoir of HIV and other viruses. ${ }^{8}$ Some of these compounds showed interesting cytostatic activity, particularly the 6arylpurinyl derivatives (which is in keeping with reports concerning 6arylpurinylribonucleosides). ${ }^{9}$

As a logical continuation of our research into the preparation and pharmacological evaluation of novel carbanucleosides derived from indan, we report here the synthesis of a new series of nucleosides in which the link between the carbacycle bearing the base (purine or pyrimidine) and the hydroxyl group is the same as in natural nucleosides. More specifically, we report the synthesis and antiviral and cytostatic activities of a series of indanylcarbanucleosides bearing purine and pyrimidine bases. 


\section{Results and discussion}

Retrosynthetic analysis (Scheme 1) led to the choice of diol trans-1 as the starting material for the prepatration of the different purine derivatives. Appropriate functionalization of trans-1 enables the coupling with 6-chloropurine under Mitsunobu conditions. This reaction leads to inversion of the configuration at the carbon bearing the secondary hydroxyl group and gives the key intermediate with a cis disposition. Acid hydrolysis of this compound gave analogue 5, which on replacement of the chlorosubstituent of the purine ring gave the 6-substituted purinylcarbanucleosides $\mathbf{6}, \mathbf{1 5}$ and 17, while Suzuki-Miyaura cross-coupling with appropriate boronic acids would give 6arylpurinylcarbanucleosides $\mathbf{9}$ and $\mathbf{1 0}$.

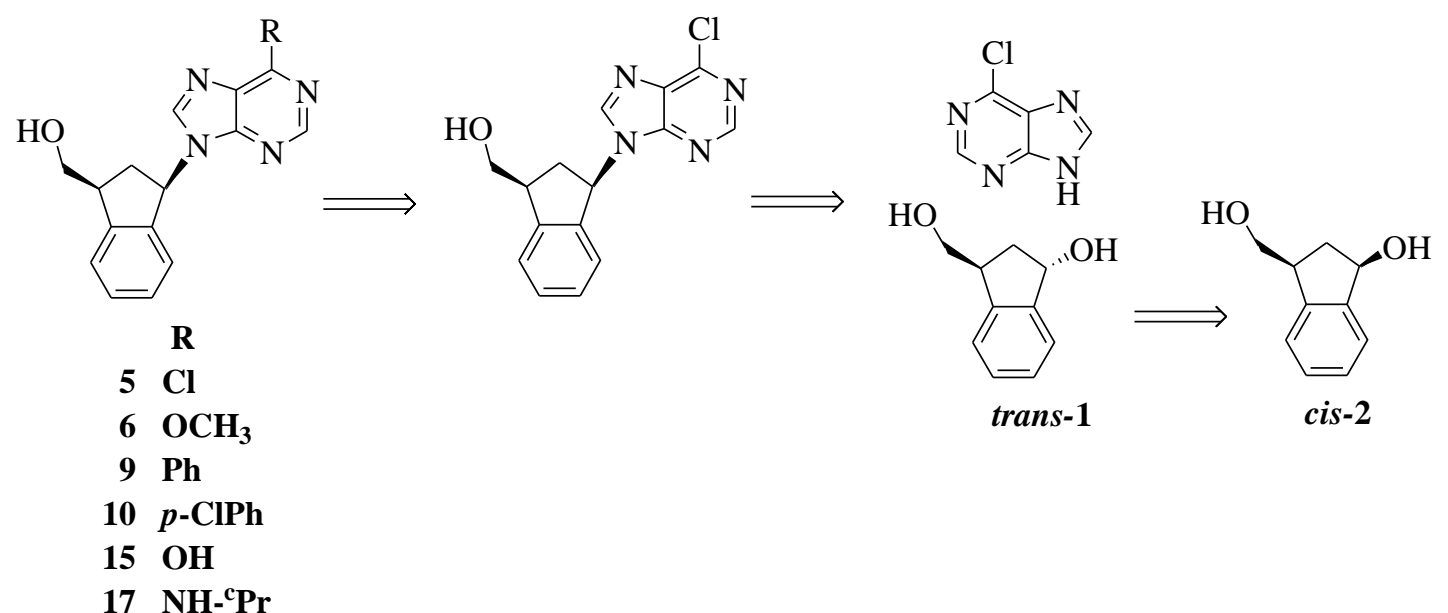

Scheme 1

Diol trans-1 was obtained from phenylsuccinic anhydride by Friedel-Crafts reaction with aluminium trichloride in 1,2-dichloroethane followed by esterification with methanol in sulphuric acid ${ }^{10}$ and treatment with lithium borohydride in tetrahydrofuran. In this way a 17:83 mixture of ( \pm )-trans-1 and ( \pm -cis-2 was obtained and this was efficiently resolved by chromatography on silica gel. ${ }^{7 \mathrm{a}}$ Diol $( \pm)$-trans-1 is the starting material required to obtain analogues with a cis disposition, but this compound was only obtained in small quantities. As a result, we decided to use the diol $( \pm)$-cis-2 as a starting material as this could be transformed into $( \pm)$-trans-1 through a Mitsunobu reaction with benzoic acid. Protection of the primary alcohol in trans-1 was achieved by enzymatic transesterification with vinyl acetate using Candida antarctica lipase (Novozym $\left.{ }^{\circledR} 435\right)^{11}$ to give the monoacetylated derivative 3 as the only product in $93 \%$ yield. 6-Chloropurine was condensed with $\mathbf{3}$ by a standard Mitsunobu reaction, ${ }^{12}$ in the presence of triethylphosphine and diethyl azodicarboxylate, to give the key intermediate 
4 in $46 \%$ yield. Treatment of 4 with $2 \mathrm{~N}$ hydrochloric acid in tetrahydrofuran gave 6chloropurinylcarbanucleoside $\mathbf{5}$ in $40 \%$ yield. Subsequent treatment of $\mathbf{5}$ with $\mathrm{MeONa}$ in $\mathrm{MeOH}$ gave 6-methoxypurinylcarbanucleoside 6 in $99 \%$ yield. On the other hand, on following the conditions reported by Hocek and co-workers, ${ }^{13}$ the chloro-substituent in position 6 of the purine was replaced in a Suzuki-Miyaura cross coupling reaction with 4 and different arylboronic acids in dry toluene containing tetrakis(triphenylphospine)palladium as a catalyst and potassium carbonate as a base. ${ }^{14}$ This procedure gave 46-65\% yields of compounds 7 and 8. Deprotection of these compounds with $\mathrm{MeONa}$ in $\mathrm{MeOH}$ afforded the 6-arylpurinylcarbanucleosides 9 and $\mathbf{1 0}$ in yields of $68-71 \%$ (Scheme 2).

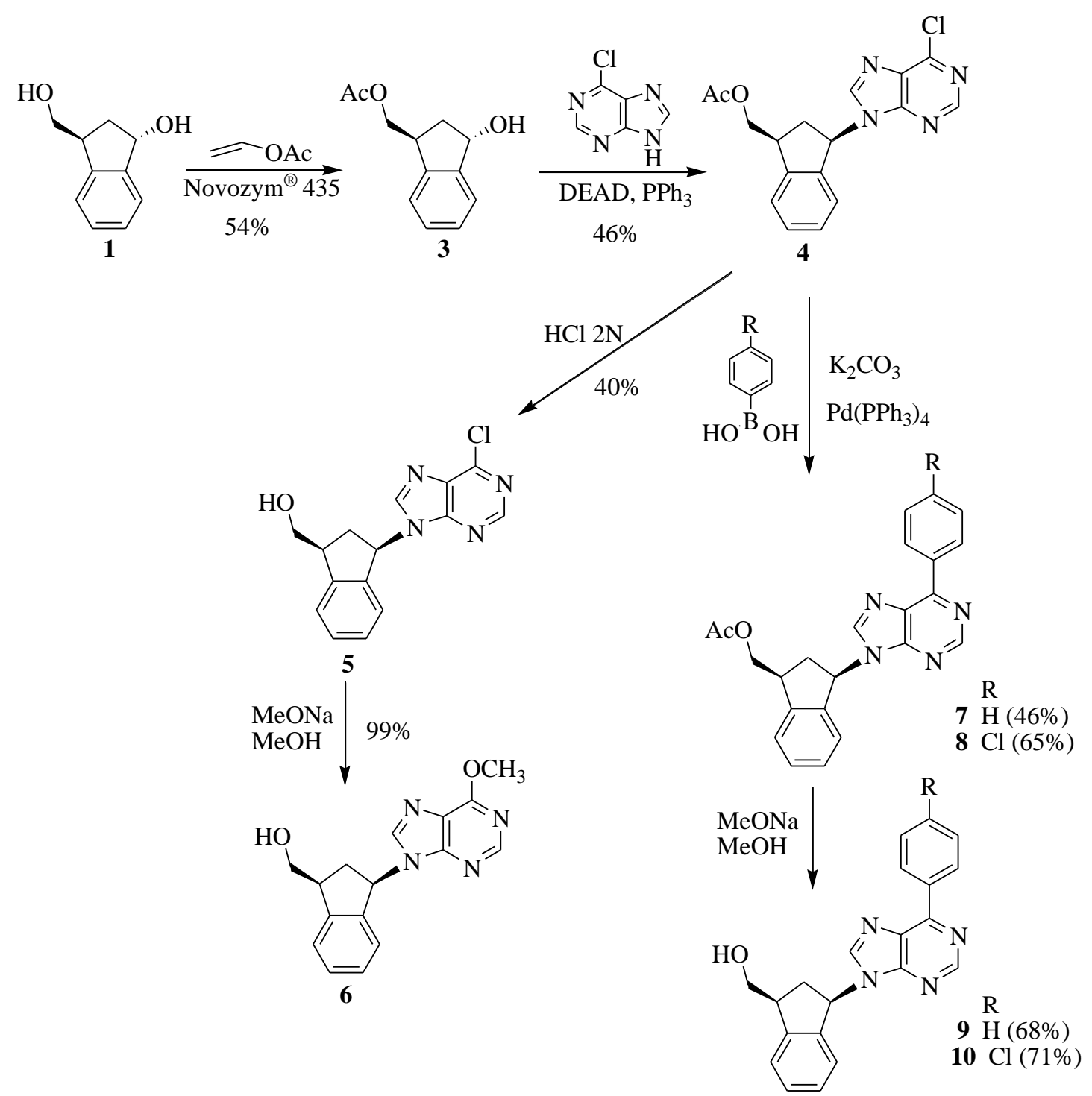

Scheme 2 
The primary alcohol of cis-2 was protected by reaction with tert-butyldimethylsilyl chloride and imidazole in dichloromethane, ${ }^{15}$ and the secondary alcohol of the resulting compound 11 was reacted with benzoic acid under Mitsunobu conditions to give compound 12 in $75 \%$ yield. Compound 12 had the required trans disposition. Deprotection of the secondary alcohol using $\mathrm{MeONa}$ in $\mathrm{MeOH}$ gave the key intermediate 13 in 95\% yield. Compound 13 was used in the coupling with 6chloropurine, through a Mitsunobu reaction, to give 6-chloropurinylcarbanucleoside $\mathbf{1 4}$ in $24 \%$ yield (with a cis disposition). Treatment of 14 with $0.25 \mathrm{~N} \mathrm{NaOH}$ in 1,4-dioxane afforded the 6-hydroxypurinylcarbanucleoside 15 in one step and in $73 \%$ yield, while treatment with $N$-cyclopropylamine in tetrahydrofuran followed by deprotection with a 3:1 mixture of trifluoroacetic acid/water gave the 6-methoxypurinylcarbanucleoside $\mathbf{1 7}$ in an overall yield of $28 \%$ (Scheme 3 ).<smiles>OCC1CC(O)c2ccccc21</smiles>

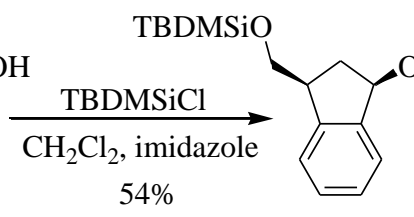

11

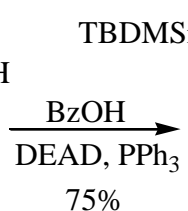

$75 \%$

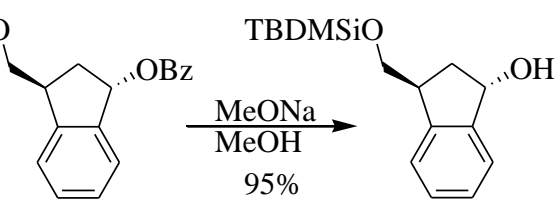

12

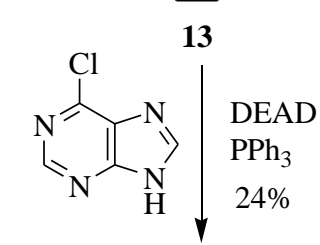

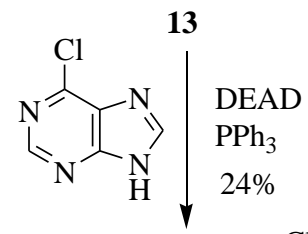

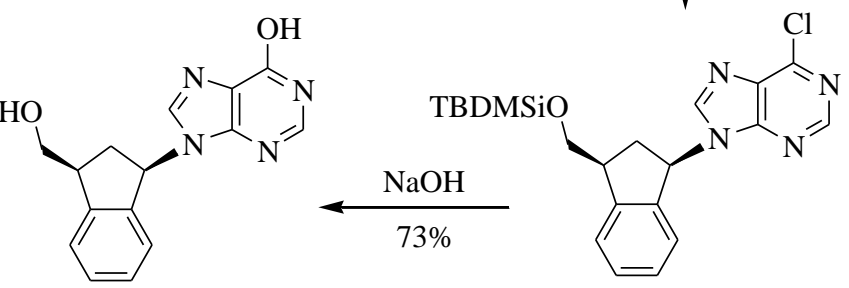

15<smiles>OC[C@H]1C[C@@H](n2cnc3c(NC4CC4)ncnc32)c2ccccc21</smiles>

17
14

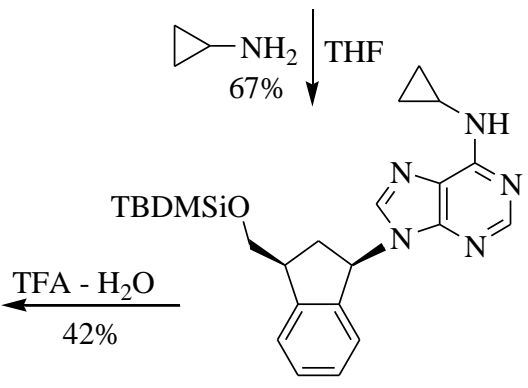

16

Scheme 3 
Finally, the 5-halouracilcarbanucleosides 19, 20 and 21 (Scheme 4) were obtained by reaction of uracilcarbanucleoside $\mathbf{1 8}$, previously reported by ourselves, ${ }^{16}$ with the corresponding $N$-halosuccinimide in DMF (19; $25 \%$ and $2073 \%)$ or $\mathrm{AcOH}(\mathbf{2 1} ; 60 \%) .{ }^{17}$

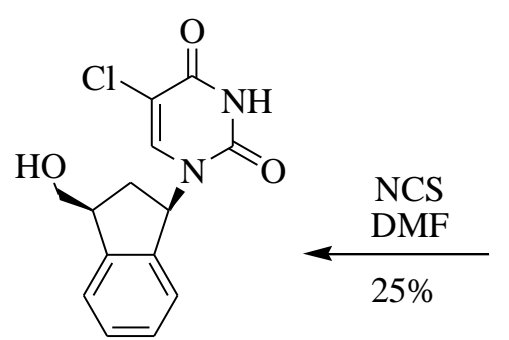

19

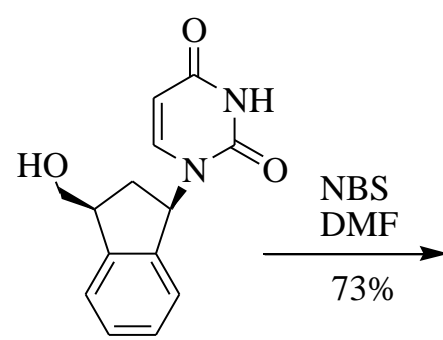

18<smiles>O=c1[nH]c(=O)n([C@@H]2C[C@H](O)c3ccccc32)cc1Br</smiles>

20

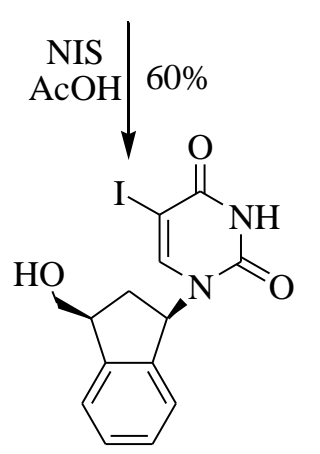

21

\section{Scheme 4}

Compounds 5, 6, 9, 10, 15, 17, 19, 20 and 21 were evaluated for antiviral activity ${ }^{18}$ against a wide variety of viruses, including Cytomegalovirus (AD 169 and Davis strains), Varicella-zoster virus (OKA and 07/1 strains), Herpes simplex virus type 1 (strain KOS), Herpes simplex virus type 2 (strain G), Vaccinia virus and Vesicular stomatitis virus in HEL cell cultures; Coxsackie virus B4, Respiratory syncytial virus and Vesicular stomatitis virus in HeLa cell cultures; Para-influenza-3 virus, Sindbis, Coxsackie virus B4 and Punta Toro virus in Vero cell cultures; Influenza A virus (H1N1 and H3N2 subtypes) and Influenza B virus in MDCK cell cultures; and Feline Corona virus and Feline Herpes Virus in CRFK cell cultures. The most outstanding results were obtained for compound $\mathbf{1 0}$, which showed moderate antiviral effects against Varicella-zoster virus (OKA strain), Vaccinia virus, Herpes simplex virus-1 (KOS) and Herpes simplex virus-2 (G) in HEL cell cultures with $\mathrm{EC}_{50}$ values of 6.0, 12, 12 and 12 $\mu \mathrm{g} / \mathrm{mL}$, respectively, and compounds $\mathbf{5}$ and $\mathbf{9}$, which showed moderate antiviral effects against Coxsackie virus B4 in Vero cell cultures with $\mathrm{EC}_{50}$ values of $12 \mu \mathrm{g} / \mathrm{mL}$. 


\section{Conclusions}

In summary, we have described the synthesis of nine novel carbocyclic nucleosides that are indan derivatives $(5,6,9,10,15,17,19,20$ and 21) with a pseudosugar based on indanol, a template in which the double bond of the cyclopentenyl nucleosides is embedded in a benzene ring. Evaluation of the antiviral activity of these compounds showed that compounds $\mathbf{5 , 9}$ and $\mathbf{1 0}$ had moderate antiviral effects.

\section{Experimental Section}

\section{General Methods}

Silica gel (230 mesh) was purchased from Merck. All other chemicals used were of reagent grade and were obtained from Aldrich Chemical Co. Melting points were determined using a Reichert Kofler Thermopan or in capillary tubes on a Büchi 510 apparatus, and are uncorrected. Infrared spectra were recorded on a Perkin-Elmer 1640FT spectrophotometer. ${ }^{1} \mathrm{H}$ NMR spectra (300 MHz) and ${ }^{13} \mathrm{C}$ NMR spectra $(75.47 \mathrm{MHz})$ were recorded on a Bruker AMX spectrometer, using TMS as internal standard (chemical shifts $(\delta)$ in ppm, $J$ in $\mathrm{Hz}$ ). Elemental analyses were obtained on a PerkinElmer 240B microanalyser by the Microanalysis Service of the University of Santiago de Compostela. Flash chromatography was performed on silica gel (Merck 60, 230-240 mesh) and analytical TLC on pre-coated silica gel plates (Merck 60 F254, $0.25 \mathrm{~mm}$ ).

\section{( \pm )-trans-3-Hydroxymethyl-1-indanol, 1,and ( \pm )-cis-3-hdroxymethyl-1-indanol, 2.}

A solution of methyl-3-oxo-1-indanecarboxylate ${ }^{6 \mathrm{a}}(12.48 \mathrm{~g}, 70.61 \mathrm{mmol})$ in dry THF was added dropwise under argon to a suspension of $\mathrm{LiBH}_{4}(8.09 \mathrm{~g}, 353.06 \mathrm{mmol})$ in the same solvent. The mixture was stirred for $12 \mathrm{~h}$ and saturated aqueous $(40 \mathrm{~mL})$ was added dropwise at $0^{\circ} \mathrm{C}$. The resulting mixture was filtered through Celite and the aqueous and organic phases were separated. The aqueous phase was extracted with AcOEt $(3 \times 100 \mathrm{~mL})$ and the combined organic phases were washed with saturated $\mathrm{NaCl}$ solution, dried over anhydrous $\mathrm{Na}_{2} \mathrm{SO}_{4}$, and concentrated under vacuum. Chromatography of the resulting yellow oil on a column of silica gel (295 g) with 40:1 $\mathrm{CH}_{2} \mathrm{Cl}_{2} / \mathrm{PrOH}$ as eluent afforded cis-2 in the early fractions [as an oil that spontaneously solidified; $8.22 \mathrm{~g}, 50.06 \mathrm{mmol}$, yield $78 \%$; M.p. $78-80{ }^{\circ} \mathrm{C}$ $\left(\mathrm{Et}_{2} \mathrm{O} /\right.$ cyclohexane)] and trans-1 in the late fractions (as a yellow oil; $1.76 \mathrm{~g}, 10.71$ mmol, yield 15\%). 
(士)-cis-2.

IR (KBr): $v=3250,2984,2933,1461,1407,1379,1281,1263,1211,1173,1067$, 1051, 1025, 777, 743, $577 \mathrm{~cm}^{-1} .{ }^{1} \mathrm{H}$ NMR $\left(\mathrm{CDCl}_{3}\right): \delta=1.74-1.81(\mathrm{~m}, 1 \mathrm{H}, 2 \beta-\mathrm{H}), 2.20-$ $2.40\left(\mathrm{~m}, 1 \mathrm{H},-\mathrm{OH}\right.$, exchangeable with $\left.\mathrm{D}_{2} \mathrm{O}\right), 2.49-2.57(\mathrm{~m}, 1 \mathrm{H}, 2 \alpha-\mathrm{H}), 3.20-3.50(\mathrm{~m}$, $1 \mathrm{H}, 3 \beta-\mathrm{H}), 3.40-3.50$ (b.s., $1 \mathrm{H},-\mathrm{OH}$, exchangeable with $\left.\mathrm{D}_{2} \mathrm{O}\right), 3.72-3.83(\mathrm{~m}, 2 \mathrm{H}$, $\left.\mathrm{C}_{2} \mathrm{OH}\right), 4.91-5.01(\mathrm{~m}, 1 \mathrm{H}, 1 \beta-\mathrm{H}), 7.18-7.35(\mathrm{~m}, 4 \mathrm{H}, \mathrm{ArH}),{ }^{13} \mathrm{C} \mathrm{NMR}\left(\mathrm{CDCl}_{3}\right): \delta=$ $39.37\left(\mathrm{CH}_{2}\right), 45.63(\mathrm{CH}), 65.60\left(\mathrm{CH}_{2}\right), 74.83(\mathrm{CH}), 124.56,125.24,128.02$ and 129.17 $(\mathrm{CH}), 143.77$ and 146.43 (C). Anal. calcd. for $\mathrm{C}_{10} \mathrm{H}_{12} \mathrm{O}_{2}$ : C, 73.15; H, 7.37. Found: C, $73.41 ; \mathrm{H}, 7.17$.

( \pm )-trans-1.

IR $(\mathrm{NaCl}): v=3265,2922,1455,1409,1372,1267,1205,1169,1054,1045,768,745$, $573 \mathrm{~cm}^{-1} .{ }^{1} \mathrm{H}$ NMR $\left(\mathrm{CDCl}_{3}\right): \delta=2.02-2.13(\mathrm{~m}, 1 \mathrm{H}, 2 \beta-\mathrm{H}), 2.24-2.34(\mathrm{~m}, 1 \mathrm{H}, 2 \alpha-\mathrm{H})$, 3.43-3.50 (m, $1 \mathrm{H}, 3 \beta-\mathrm{H}), 3.68-3.70\left(\mathrm{~m}, 2 \mathrm{H}, \mathrm{C}_{2} \mathrm{OH}\right), 5.22-5.26(\mathrm{~m}, 1 \mathrm{H}, 1 \alpha-\mathrm{H}), 7.23-$ $7.40(\mathrm{~m}, 4 \mathrm{H}, \mathrm{ArH}) .{ }^{13} \mathrm{C} \mathrm{NMR}\left(\mathrm{CDCl}_{3}\right): \delta=47.06\left(\mathrm{CH}_{2}\right), 52.87(\mathrm{CH}), 73.73\left(\mathrm{CH}_{2}\right)$, $82.85(\mathrm{CH}), 132.20,132.38,135.36$ and $136.31(\mathrm{CH}), 151.12$ and $153.27(\mathrm{C})$. Anal. calcd. for $\mathrm{C}_{10} \mathrm{H}_{12} \mathrm{O}_{2}$ : C, 73.15; H, 7.37. Found: C, 73.36; H, 7.13.

(土)-trans-3-Hydroxy-1-indanylmethyl acetate, 3 .

A suspension of the lipase Novozym ${ }^{\circledR} 435(0.140 \mathrm{~g} ; 0.321 \mathrm{mmol})$ and diol 1 (0.550 g; $3.35 \mathrm{mmol})$ in THF $(25 \mathrm{~mL})$, at $0^{\circ} \mathrm{C}$ under an argon atmosphere, was added a solution of vinyl acetate $(0.32 \mathrm{~mL} ; 3.35 \mathrm{mmol})$ in THF $(30 \mathrm{~mL})$. The mixture was stirred for $4 \mathrm{~h}$ at $0^{\circ} \mathrm{C}$ and then at room temperature for $68 \mathrm{~h}$. The mixture was filtered through Celite and the solvent was removed under reduced pressure to give a yellow oil, which was purified by column chromatography on silica gel (30.4 g), using hexane/AcOEt (8:1) as eluent, to give 3 as a colourless oil $(0.300 \mathrm{~g}$; Yield 54\%). IR $(\mathrm{NaCl}): v=3385,1734$, 1556, 1458, 1349, 1259, 1134, 1034, 832, $738 \mathrm{~cm}^{-1} .{ }^{1} \mathrm{H}$ NMR $\left(\mathrm{CDCl}_{3}\right): \delta=2.06(\mathrm{~s}, 3 \mathrm{H}$, $\left.\mathrm{CH}_{3}\right), 2.17-2.27(\mathrm{~m}, 2 \mathrm{H}, 2 \beta-\mathrm{H}+2 \alpha-\mathrm{H}), 3.64-3.70(\mathrm{~m}, 1 \mathrm{H}, 1 \beta-\mathrm{H}), 4.10-4.25(\mathrm{~m}, 2 \mathrm{H}$, $\left.\mathrm{C}_{2} \mathrm{OAc}\right), 5.28-5.33(\mathrm{~m}, 1 \mathrm{H}, 3 \alpha-\mathrm{H}), 7.26-7.45(\mathrm{~m}, 4 \mathrm{H}, \mathrm{ArH}) .{ }^{13} \mathrm{C} \mathrm{NMR}\left(\mathrm{CDCl}_{3}\right): \delta=$ $21.38\left(\mathrm{CH}_{3}\right), 40.10\left(\mathrm{CH}_{2}\right), 42.24(\mathrm{CH}), 67.82\left(\mathrm{CH}_{2}\right), 75.46(\mathrm{CH}), 124.98,125.14$, 128.29 and $129.14(\mathrm{CH}), 143.40,145.61,171.54(\mathrm{C})$. Anal. calcd. for $\mathrm{C}_{12} \mathrm{H}_{14} \mathrm{O}_{3}: \mathrm{C}$, 69.88; H, 6.84. Found: C, 70.03; H, 6.99. 
( \pm )-cis-3-(6-Chloro-9H-purin-9-yl)indanylmethyl acetate, 4.

To a solution of $3(0.42 \mathrm{~g} ; 2.03 \mathrm{mmol}), \mathrm{PPh}_{3}(1.07 \mathrm{~g} ; 4.06 \mathrm{mmol})$ and 6-chloropurine $(0.63 \mathrm{~g} ; 4.06 \mathrm{mmol})$ in THF $(20 \mathrm{~mL})$, under an argon atmosphere at $0^{\circ} \mathrm{C}$, was added dropwise a solution of DEAD $(1.86 \mathrm{~mL} ; 4.06 \mathrm{mmol})$ in THF $(15 \mathrm{~mL})$. The mixture was stirred at $0^{\circ} \mathrm{C}$ for $1 \mathrm{~h}$ and at room temperature for $65 \mathrm{~h}$. The solvent was removed under reduced pressure to give a solid, which was purified by column chromatography on silica gel (113 g), using hexane/AcOEt (2:1) as eluent, to give an oil that crystallised spontaneously to give a colourless solid $(0.17 \mathrm{~g}$; Yield $46 \%)$. This product was identified as $\left( \pm\right.$ )-cis-3-(6-chloro-9H-purin-9-yl)indanylmethyl acetate, 4. M.p.: 35-38 ${ }^{\circ} \mathrm{C}$ (pentane). IR (KBr): v = 2979, 1731, 1591, 1578, 1557, 1497, 1436, 1402, 1354, 1336, 1236, 1040, 941, $859763 \mathrm{~cm}^{-1} .{ }^{1} \mathrm{H}$ NMR $\left(\mathrm{CDCl}_{3}\right): \delta=2.05\left(\mathrm{~s}, 3 \mathrm{H}, \mathrm{CH}_{3}\right), 2.06-2.17(\mathrm{dt}$, $\left.1 \mathrm{H}, J_{(\mathrm{t})}=13.64 \mathrm{~Hz}, J_{(\mathrm{d})}=7.75 \mathrm{~Hz}, 2 \beta-\mathrm{H}\right), 3.05-3.17\left(\mathrm{dt}, 1 \mathrm{H}, J_{(\mathrm{t})}=13.64 \mathrm{~Hz}, J_{(\mathrm{d})}=8.29\right.$ $\mathrm{Hz}, 2 \alpha-\mathrm{H}), 3.60-3.71(\mathrm{~m}, 1 \mathrm{H}, 1 \beta-\mathrm{H}), 4.26-4.34$ (Part A of an ABM system, $1 \mathrm{H}, J_{\mathrm{AB}}=$ $11.72 \mathrm{~Hz}, J_{\mathrm{AM}}=6.90 \mathrm{~Hz},-\mathrm{C}$ HHOAc), $4.38-4.45$ (Part B of an ABM system, $1 \mathrm{H}, J_{\mathrm{BA}}=$ $\left.11.72 \mathrm{~Hz}, J_{\mathrm{BM}}=6.62 \mathrm{~Hz},-\mathrm{CH} \underline{\mathrm{HOAc}}\right), 6.24-6.31(\mathrm{t}, 1 \mathrm{H}, J=8.29 \mathrm{~Hz}, 3 \beta-\mathrm{H}), 7.05-7.08$ (d, 1H, J=8.0 Hz, ArH), 7.26-7.44 (m, 3H, ArH), 7.99 (s, 1H, 8'-H), 8.77 (s, 1H, 2'-H). ${ }^{13} \mathrm{C}$ NMR $\left(\mathrm{CDCl}_{3}\right): \delta=20.34\left(\mathrm{CH}_{3}\right), 37.12\left(\mathrm{CH}_{2}\right), 41.50(\mathrm{CH}), 57.76(\mathrm{CH}), 65.93$ $\left(\mathrm{CH}_{2}\right), 123.88,124.26,127.99$ and $129.17(\mathrm{CH}), 131.28(\mathrm{C}), 138.88(\mathrm{C}), 142.66(\mathrm{C})$, $143.20(\mathrm{CH}), 150.66(\mathrm{C}), 151.44(\mathrm{CH}), 156.21(\mathrm{C})$ and $170.40(\mathrm{C})$. Anal. calcd. for $\mathrm{C}_{17} \mathrm{H}_{15} \mathrm{ClN}_{4} \mathrm{O}_{2}$ : C, 59.57; H, 4.41; N, 16.34. Found: C, 59.36; H, 4.73; N, 16.56.

( \pm )-cis-3-(6-Chloro-9H-purin-9-yl)-1-indanylmethanol, 5.

To a solution of $4(0.175 \mathrm{~g} ; 0.510 \mathrm{mmol})$ in THF was added $2 \mathrm{~N} \mathrm{HCl}(10 \mathrm{~mL})$ and the mixture was stirred for $20 \mathrm{~h}$ at $40^{\circ} \mathrm{C}$. The mixture was neutralised with $2 \mathrm{~N} \mathrm{NaOH}(12$ $\mathrm{mL}$ ) and the solvent was removed under reduced pressure followed by several coevaporations with toluene and ethanol. This process gave a colourless solid, which was purified by column chromatography on silica gel (50 g), using hexane/AcOEt (1:3) as eluent, to give compound 5 as a colourless solid (0.06 g; Yield 40\%). IR (KBr): $v=$ 3285, 2887, 1594, 1561, 1446, 1396, 1339, 1259, 927, 763, 653, $548 \mathrm{~cm}^{-1}$. ${ }^{1} \mathrm{H}$ NMR $\left(\mathrm{CDCl}_{3}\right): \delta=2.27-2.36\left(\mathrm{dt}, 1 \mathrm{H}, \mathrm{J}_{(\mathrm{t})}=13.97 \mathrm{~Hz}, \mathrm{~J}_{(\mathrm{d})}=6.53 \mathrm{~Hz}, 2 \beta-\mathrm{H}\right), 3.03-3.13(\mathrm{dt}, 1 \mathrm{H}$, $\left.\mathrm{J}_{(\mathrm{t})}=13.98 \mathrm{~Hz}, \mathrm{~J}_{(\mathrm{d})}=8.81 \mathrm{~Hz}, 2 \alpha-\mathrm{H}\right), 3.52-3.60(\mathrm{~m}, 1 \mathrm{H}, 1 \beta-\mathrm{H}), 3.95-4.12(\mathrm{~m}, 2 \mathrm{H}$, $\left.\mathrm{C}_{2} \mathrm{OH}\right), 6.25-6.30\left(\mathrm{t}, 1 \mathrm{H}, \mathrm{J}_{(\mathrm{t})}=6.81 \mathrm{~Hz}, 3 \beta-\mathrm{H}\right), 7.02-7.05\left(\mathrm{~d}, 1 \mathrm{H}, \mathrm{J}_{(\mathrm{d})}=7.61 \mathrm{~Hz}, \mathrm{ArH}\right)$, 7.24-7.29 (m, 1H, ArH), 7.37-7.42 (t, 1H, $\left.\mathrm{J}_{(\mathrm{t})}=7.56 \mathrm{~Hz}, \mathrm{ArH}\right), 7.43-7.47\left(\mathrm{t}, 1 \mathrm{H}, \mathrm{J}_{(\mathrm{t})}=\right.$ 
$7.45 \mathrm{~Hz}, \mathrm{ArH}), 8.12\left(\mathrm{~s}, 1 \mathrm{H}, 8^{\prime}-\mathrm{H}\right), 8.75\left(\mathrm{~s}, 1 \mathrm{H}, 2^{\prime}-\mathrm{H}\right) .{ }^{13} \mathrm{C} \mathrm{NMR}\left(\mathrm{CDCl}_{3}\right): \delta=36.19$ $\left(\mathrm{CH}_{2}\right), 45.28(\mathrm{CH}), 58.63(\mathrm{CH}), 64.81\left(\mathrm{CH}_{2}\right), 124.47,124.68,128.23$ and $129.66(\mathrm{CH})$, $131.71(\mathrm{C}), 140.11(\mathrm{C}), 144.02(\mathrm{C}), 144.52(\mathrm{CH}), 150.99(\mathrm{C}), 151.81(\mathrm{CH})$. Anal. calcd. for $\mathrm{C}_{15} \mathrm{H}_{13} \mathrm{ClN}_{4} \mathrm{O}$ : C, 59.91; H, 4.36; N, 18.63. Found: C, 60.15; H, 4.11; N, 18.40 .

\section{( \pm )-cis-3-(6-Methoxy-9H-purin-9-yl)-1-indanylmethanol, 6.}

To a solution of 5 (0.030 g; $0.101 \mathrm{mmol})$ in $\mathrm{MeOH}(10 \mathrm{~mL})$ was added, under an argon atmosphere, $\mathrm{MeONa}(0.11 \mathrm{~mL} ; 0.11 \mathrm{mmol})$ and the mixture was stirred for $6 \mathrm{~h}$ at room temperature. The solvent was removed under reduced pressure and the residue was purified by column chromatography on silica gel (3.15 g), using $\mathrm{CH}_{2} \mathrm{Cl}_{2} /$ isopropanol (30:1) as eluent, to give 6 as a colourless solid (0.030 g; Yield 99\%). IR $(\mathrm{NaCl}): v=$ 3394, 1602, 1480, 1316, 1229, 1056, 760, $649 \mathrm{~cm}^{-1} .{ }^{1} \mathrm{H}$ NMR $\left(\mathrm{CDCl}_{3}\right): \delta=1.65(\mathrm{~s}, 3 \mathrm{H}$, $\left.\mathrm{CH}_{3} \mathrm{CO}\right), 2.33-2.42\left(\mathrm{dt}, 1 \mathrm{H}, \mathrm{J}_{(\mathrm{t})}=13.96 \mathrm{~Hz}, \mathrm{~J}_{(\mathrm{d})}=6.98 \mathrm{~Hz}, 2 \beta-\mathrm{H}\right), 3.00-3.11\left(\mathrm{dt}, 1 \mathrm{H}, \mathrm{J}_{(\mathrm{t})}\right.$ $\left.=13.94 \mathrm{~Hz}, \mathrm{~J}_{(\mathrm{d})}=8.82 \mathrm{~Hz}, 2 \alpha-\mathrm{H}\right), 3.52-3.60(\mathrm{~m}, 1 \mathrm{H}, 1 \beta-\mathrm{H}), 3.90-4.01\left(\mathrm{~m}, 2 \mathrm{H}, \mathrm{C}_{2} \mathrm{OAc}\right)$, $4.19\left(\mathrm{~s}, 3 \mathrm{H}, \mathrm{OCH}_{3}\right), 6.17-6.22\left(\mathrm{t}, 1 \mathrm{H}, \mathrm{J}_{(\mathrm{t})}=7.87 \mathrm{~Hz}, 3 \beta-\mathrm{H}\right), 7.01-7.04\left(\mathrm{~d}, 1 \mathrm{H}, \mathrm{J}_{(\mathrm{d})}=7.58\right.$ $\mathrm{Hz}, \mathrm{ArH})$, 7.23-7.31 (m, 1H, ArH), 7.36-7.46 (m, 2H, ArH), 7.88 (s, 1H, 2'-H), 8.51 (s, $\left.1 \mathrm{H}, 8^{\prime}-\mathrm{H}\right) .{ }^{13} \mathrm{C} \mathrm{NMR}\left(\mathrm{CDCl}_{3}\right): \delta=35.84\left(\mathrm{CH}_{2}\right), 45.16(\mathrm{CH}), 54.08\left(\mathrm{CH}_{3}\right), 58.41(\mathrm{CH})$, $64.82\left(\mathrm{CH}_{2}\right), 124.40,124.83,127.92$ and $129.22(\mathrm{CH}), 140.34(\mathrm{CH}), 140.58(\mathrm{CH})$, $143.59(\mathrm{C}), 144.06(\mathrm{C}), 151.73(\mathrm{CH}), 160.99$ (C). Anal. calcd. for $\mathrm{C}_{16} \mathrm{H}_{16} \mathrm{~N}_{4} \mathrm{O}_{2}: \mathrm{C}$, 64.85; H, 5.44; N, 18.91. Found: C, 65.16; H, 5.29; N, 19.13.

\section{(士)-cis-3-(6-Phenyl-9H-purin-9-yl)-1-indanylmethyl acetate, 7.}

A mixture of 4 (0.154 g; $0.83 \mathrm{mmol}), \mathrm{K}_{2} \mathrm{CO}_{3}(0.085 \mathrm{~g}$; $0.675 \mathrm{mmol})$, 6-phenylboronic acid $(0.094 \mathrm{~g} ; 0.675 \mathrm{mmol})$ and $\mathrm{Pd}\left(\mathrm{PPh}_{3}\right)_{4}(0.046 \mathrm{~g})$ in anhydrous toluene $(80 \mathrm{~mL})$ under an argon atmosphere was stirred for $12 \mathrm{~h}$ at $100^{\circ} \mathrm{C}$. The solvent was removed by vacuum distillation and the residue was purified by column chromatography on silica gel (48 g), using hexane/AcOEt (4:1) as eluent, to give 7 as a yellow oil, which crystallised spontaneously as a colourless solid (0.08 g; Yield $46 \%)$. M.p.: $38-41^{\circ} \mathrm{C}$ $\left(\mathrm{CHCl}_{3} / \mathrm{Hexane}\right.$. IR (KBr): $v=3418,2919,1734,1649,1560,1536,1457,1351,1223$, 1021, 765, $694 \mathrm{~cm}^{-1} .{ }^{1} \mathrm{H}$ NMR $\left(\mathrm{CDCl}_{3}\right): \delta=2.05\left(\mathrm{~s}, 3 \mathrm{H}, \mathrm{CH}_{3}\right), 2.09-2.21\left(\mathrm{dt}, 1 \mathrm{H}, J_{(\mathrm{t})}=\right.$ $\left.13.52 \mathrm{~Hz}, J_{(\mathrm{d})}=7.77 \mathrm{~Hz}, 2 \beta-\mathrm{H}\right), 3.08-3.20\left(\mathrm{dt}, 1 \mathrm{H}, J_{(\mathrm{t})}=13.52 \mathrm{~Hz}, J_{(\mathrm{d})}=8.18 \mathrm{~Hz}, 2 \alpha-\right.$ $\mathrm{H}), 3.62-3.73(\mathrm{~m}, 1 \mathrm{H}, 1 \beta-\mathrm{H}), 4.35-4.42$ (Part A of an ABM system, $1 \mathrm{H}, J_{\mathrm{AB}}=11.11 \mathrm{~Hz}$, $\left.J_{\mathrm{AM}}=6.30 \mathrm{~Hz},-\mathrm{C} \underline{H} H O A c\right), 4.44-4.51$ (Part B of an ABM system, $1 \mathrm{H}, J_{\mathrm{BA}}=11.11 \mathrm{~Hz}$, $\left.J_{\mathrm{BM}}=5.59 \mathrm{~Hz},-\mathrm{CH} \underline{\mathrm{HOAc}}\right), 6.31-6.38(\mathrm{t}, 1 \mathrm{H}, J=7.89 \mathrm{~Hz}, 3 \beta-\mathrm{H}), 7.10-7.13(\mathrm{~d}, 1 \mathrm{H}, J=$ 
$7.62 \mathrm{~Hz}, \mathrm{ArH}), 7.26-7.61$ (m, 6H, ArH), 7.98 (s, 1H, 8'-H), 8.78-8.81 (d, 2H, $J=7.63$ $\mathrm{Hz}, \mathrm{ArH}), 9.06\left(\mathrm{~s}, 1 \mathrm{H}, 2{ }^{\prime}-\mathrm{H}\right) .{ }^{13} \mathrm{C}$ NMR $\left(\mathrm{CDCl}_{3}\right): \delta=21.31\left(\mathrm{CH}_{3}\right), 38.29\left(\mathrm{CH}_{2}\right), 42.46$ $(\mathrm{CH}), 58.02(\mathrm{CH}), 66.97\left(\mathrm{CH}_{2}\right), 124.94,125.15,128.83,129.10,129.88$ and 130.20 $(\mathrm{CH}), 131.43(\mathrm{C}), 136.08(\mathrm{C}), 143.06(\mathrm{CH}), 143.61(\mathrm{C}), 152.83(\mathrm{CH})$ and $171.34(\mathrm{C})$. Anal. calcd. for $\mathrm{C}_{23} \mathrm{H}_{20} \mathrm{~N}_{4} \mathrm{O}_{2}$ : C, 71.86; H, 5.24; N, 14.57. Found: C, 71.61; H, 5.03; N, 14.80 .

(士)-cis-3-[6-(4'-Chloro)phenyl-9H-purin-9-yl)-1-indanylmethyl acetate, 8.

Reaction of 4 with 6-chlorophenylboronic acid, following an identical procedure to that described in section 5.7, gave $\mathbf{8}$ as a clear oil that spontaneously crystallised to a colourless solid. (Yield 65\%). M.p. $60-63^{\circ} \mathrm{C}\left(\mathrm{CHCl}_{3} / \mathrm{Hexane}\right) . \mathrm{IR}(\mathrm{KBr}): v=3412$, 1734, 1649, 1578, 1514, 1496, 1469, 1445, 1325, 1221, 1014, 843, 803, 747, $646 \mathrm{~cm}^{-1}$. ${ }^{1} \mathrm{H} \mathrm{NMR}\left(\mathrm{CDCl}_{3}\right): \delta=2.04\left(\mathrm{~s}, 3 \mathrm{H}, \mathrm{CH}_{3}\right), 2.09-2.19\left(\mathrm{dt}, 1 \mathrm{H}, J_{(\mathrm{t})}=13.58 \mathrm{~Hz}, J_{(\mathrm{d})}=7.70\right.$ $\mathrm{Hz}, 2 \beta-\mathrm{H}), 3.07-3.17\left(\mathrm{dt}, 1 \mathrm{H}, J_{(\mathrm{t})}=13.58 \mathrm{~Hz}, J_{(\mathrm{d})}=8.10 \mathrm{~Hz}, 2 \alpha-\mathrm{H}\right), 3.64-3.71(\mathrm{~m}, 1 \mathrm{H}$, $1 \beta-\mathrm{H}), 4.35-4.41$ (Part A of an ABM system, $1 \mathrm{H}, J_{\mathrm{AB}}=11.11 \mathrm{~Hz}, J_{\mathrm{AM}}=6.30 \mathrm{~Hz}$, CㅍHOAc), 4.43-4.48 (Part B of an ABM system, $1 \mathrm{H}, J_{\mathrm{BA}}=11.11 \mathrm{~Hz}, J_{\mathrm{BM}}=5.58 \mathrm{~Hz}$, -

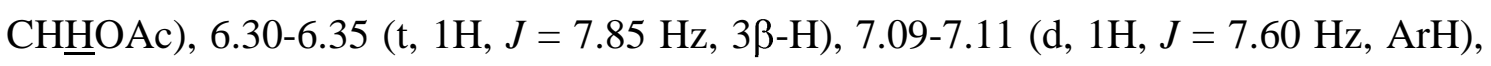
7.26-7.49 (m, 3H, ArH), 7.50-7.53 (d, 2H, J = 8.57 Hz, ArH), 7.97 (s, 1H, 8'-H), 8.78$8.81(\mathrm{~d}, 2 \mathrm{H}, J=8.57 \mathrm{~Hz}, \mathrm{ArH}), 9.02\left(\mathrm{~s}, 1 \mathrm{H}, 2^{\prime}-\mathrm{H}\right) .{ }^{13} \mathrm{C} \mathrm{NMR}\left(\mathrm{CDCl}_{3}\right): \delta=21.27\left(\mathrm{CH}_{3}\right)$, $38.21\left(\mathrm{CH}_{2}\right), 42.47(\mathrm{CH}), 58.07(\mathrm{CH}), 66.96\left(\mathrm{CH}_{2}\right), 124.91,125.17,128.83,129.31$, 129.91 and $131.52(\mathrm{CH}), 131.58(\mathrm{C}), 134.56(\mathrm{C}), 137.67(\mathrm{C}), 140.37(\mathrm{C}), 143.22(\mathrm{CH})$, $143.63(\mathrm{C}), 152.76(\mathrm{CH}), 153.19(\mathrm{C}), 154.02(\mathrm{C})$ and $171.30(\mathrm{C})$. Anal. calcd. for $\mathrm{C}_{23} \mathrm{H}_{19} \mathrm{ClN}_{4} \mathrm{O}_{2}$ : C, 65.95; H, 4.57; N, 13.38. Found: C, 66.22; H, 4.35; N, 13.57.

( \pm )-cis-3-(6-Phenyl-9H-purin-9-yl)-1-indanylmethanol, 9.

To a solution of $7(0.05 \mathrm{~g}$; $0.13 \mathrm{mmol})$ in $\mathrm{MeOH}(5 \mathrm{~mL})$, under an argon atmosphere, was added powdered $95 \% \mathrm{MeONa}(0.015 \mathrm{~g} ; 0.264 \mathrm{mmol})$ and the mixture was stirred for $20 \mathrm{~h}$. The solution was neutralised by the addition of Dowex $50 \times 8\left(\mathrm{H}^{+}\right)$resin $(c a$. $100 \mathrm{mg}$ ) and the mixture was stirred for $20 \mathrm{~min}$. The resin was filtered off and washed with $\mathrm{MeOH}$ saturated with ammonia $(10 \mathrm{~mL})$ and $\mathrm{MeOH}(10 \mathrm{~mL})$. The filtrates were combined and concentrated to dryness. The resulting colourless solid was purified by column chromatography on silica gel (6 g), using hexane/AcOEt (1:2) as eluent, to give 9 as a colourless solid. (0.034 g; Yield 68\%). M.p. 53-56 ${ }^{\circ} \mathrm{C}\left(\mathrm{CHCl}_{3} / \mathrm{Hexane}\right)$. IR ( $\left.\mathrm{KBr}\right)$ : $v=3378,2921,1654,1562,1499,1488,1457,1416,1399,1350,1325,1265,1218$, 
1131, 1030, 828, 764, 694, $647 \mathrm{~cm}^{-1} .{ }^{1} \mathrm{H} \mathrm{NMR}\left(\mathrm{CDCl}_{3}\right): \delta=2.28-2.40\left(\mathrm{dt}, 1 \mathrm{H}, J_{(\mathrm{t})}=\right.$ $\left.13.85 \mathrm{~Hz}, J_{(\mathrm{d})}=7.10 \mathrm{~Hz}, 2 \beta-\mathrm{H}\right), 2.95-3.07\left(\mathrm{dt}, 1 \mathrm{H}, J_{(\mathrm{t})}=13.85 \mathrm{~Hz}, J_{(\mathrm{d})}=8.70 \mathrm{~Hz}, 2 \alpha-\right.$ $\mathrm{H}), 3.44-3.54(\mathrm{~m}, 1 \mathrm{H}, 1 \beta-\mathrm{H}), 3.88-3.94$ (Part A of an ABM system, $1 \mathrm{H}, J_{\mathrm{AB}}=10.74 \mathrm{~Hz}$, $\left.J_{\mathrm{AM}}=4.12 \mathrm{~Hz},-\mathrm{C} \underline{\mathrm{HHOH}}\right), 3.99-4.05$ (Part B of an ABM system, $1 \mathrm{H}, J_{\mathrm{BA}}=10.74 \mathrm{~Hz}$, $\left.J_{\mathrm{BM}}=6.377 \mathrm{~Hz},-\mathrm{CH} \underline{\mathrm{HOH}}\right), 6.19-6.26(\mathrm{t}, 1 \mathrm{H}, J=7.56 \mathrm{~Hz}, 3 \beta-\mathrm{H}), 6.97-7.01(\mathrm{~d}, 1 \mathrm{H}, J=$ $7.56 \mathrm{~Hz}, \mathrm{ArH}), 7.08-7.53$ (m, 6H, ArH), 8.03 (s, 1H, 8'-H), 8.67-8.71 (d, 2H, J = 7.68 $\mathrm{Hz}, \mathrm{ArH}), 8.93\left(\mathrm{~s}, 1 \mathrm{H}, 2^{\prime}-\mathrm{H}\right) .{ }^{13} \mathrm{C} \mathrm{NMR}\left(\mathrm{CDCl}_{3}\right): \delta=36.00\left(\mathrm{CH}_{2}\right), 45.16(\mathrm{CH}), 58.09$ $(\mathrm{CH}), 64.84\left(\mathrm{CH}_{2}\right), 124.36(\mathrm{CH}), 124.48(\mathrm{C}), 128.01,128.11,128.58,128.93,129.32$ and $129.70(\mathrm{CH}), 130.91(\mathrm{C}), 135.52(\mathrm{C}), 140.60(\mathrm{C}), 143.36(\mathrm{CH}), 143.68(\mathrm{C}), 152.06$ (CH), 154.98 (C). Anal. calcd. for $\mathrm{C}_{21} \mathrm{H}_{18} \mathrm{~N}_{4} \mathrm{O}$ : C, 73.67; H, 5.30; N, 16.36. Found: C, $73.30 ; \mathrm{H}, 5.51 ; \mathrm{N}, 16.61$.

\section{(士)-cis-3-[(6-(4'-Chloro)phenyl-9H-purin-9-yl)-1-indanylmethanol, 10.}

The same procedure as described in section $\mathbf{5 . 9}$ was used to prepare $\mathbf{1 0}$ from $\mathbf{8}$. (Yield 71\%). M.p. 56-59 ${ }^{\circ} \mathrm{C}\left(\mathrm{CHCl}_{3} / \mathrm{Hexane}\right)$. IR (KBr): v = 2922, 1582, 1518, 1497, 1485, 1447, 1416, 1386, 1344, 1261, 1240, 1086, 802, 757, $649 \mathrm{~cm}^{-1} .{ }^{1} \mathrm{H}$ NMR $\left(\mathrm{CDCl}_{3}\right): \delta=$ 1.19-1.23 (b.s., $1 \mathrm{H}, \mathrm{OH}$ exchangeable with $\left.\mathrm{D}_{2} \mathrm{O}\right), 2.33-2.45\left(\mathrm{dt}, 1 \mathrm{H}, J_{(\mathrm{t})}=13.85 \mathrm{~Hz}, J_{(\mathrm{d})}\right.$ $=7.02 \mathrm{~Hz}, 2 \beta-\mathrm{H}), 3.05-3.17\left(\mathrm{dt}, 1 \mathrm{H}, J_{(\mathrm{t})}=13.85 \mathrm{~Hz}, J_{(\mathrm{d})}=7.67 \mathrm{~Hz}, 2 \alpha-\mathrm{H}\right), 3.59-3.64$ (m, $1 \mathrm{H}, 1 \beta-\mathrm{H}), 3.99-4.15\left(\mathrm{~m}, 2 \mathrm{H}, \mathrm{CH}_{2} \mathrm{OH}\right), 6.28-6.35(\mathrm{~m}, 1 \mathrm{H}, 3 \beta-\mathrm{H}), 7.05-7.08(\mathrm{~d}, 1 \mathrm{H}$, $J=7.55 \mathrm{~Hz}, \mathrm{ArH}), 7.26-7.47$ (m, 3H, ArH), 7.51-7.53 (d, 2H, $J=8.66 \mathrm{~Hz}, \operatorname{ArH}), 8.12$ $\left(\mathrm{s}, 1 \mathrm{H}, 8^{\prime}-\mathrm{H}\right), 8.78-8.81(\mathrm{~d}, 2 \mathrm{H}, J=8.66 \mathrm{~Hz}, \operatorname{ArH}), 8.99\left(\mathrm{~s}, 1 \mathrm{H}, 2{ }^{\prime}-\mathrm{H}\right) .{ }^{13} \mathrm{C} \mathrm{NMR}$ $\left(\mathrm{CDCl}_{3}\right): \delta=36.09\left(\mathrm{CH}_{2}\right), 42.23(\mathrm{CH}), 58.26(\mathrm{CH}), 64.97\left(\mathrm{CH}_{2}\right), 124.47,124.58$, 128.19, 128.93, 129.50 and $131.11(\mathrm{CH}), 131.43(\mathrm{C}), 134.13(\mathrm{C}), 137.27(\mathrm{C}), 140.66$ (C), $143.56(\mathrm{CH}), 143.70$ and 152.17 (C). Anal. calcd. for $\mathrm{C}_{21} \mathrm{H}_{17} \mathrm{ClN}_{4} \mathrm{O}: \mathrm{C}, 66.93 ; \mathrm{H}$, 4.55; N, 14.87. Found: C, 67.19; H, 4.76; N, 14.59.

\section{( \pm )-cis-3-(tert-Butyldimethylsilyloxy)methylindanol, 11.}

To a suspension of diol 2 (1.6 g; $8.37 \mathrm{mmol})$ and imidazole $(1.13 \mathrm{~g} ; 16.74 \mathrm{mmol})$ in anhydrous dichloromethane $(60 \mathrm{~mL})$ was added, at $0^{\circ} \mathrm{C}$ under an argon atmosphere, a solution of tert-butyldimethylsilyl chloride (1.35 g; $9.21 \mathrm{mmol})$ in anhydrous dichloromethane $(20 \mathrm{~mL})$. The mixture was cooled to $0-5^{\circ} \mathrm{C}$ and stirred for $24 \mathrm{~h}$. The mixture was allowed to warm up to room temperature and stirred for $1 \mathrm{~h}$. Dichloromethane $(60 \mathrm{~mL})$ was added and the solution was extracted $\mathrm{NaHCO}_{3}(80 \mathrm{~mL})$. The aqueous phase was extracted with dichloromethane $(3 \times 50 \mathrm{~mL})$ and the combined 
organic phases were washed with saturated aqueous $\mathrm{NH}_{4} \mathrm{Cl}(100 \mathrm{~mL})$ and dried $\left(\mathrm{Na}_{2} \mathrm{SO}_{4}\right)$. The solvent was evaporated to give a yellow oil, which was purified by column chromatography on silica gel (84 g), using hexane/AcOEt (12:1) as eluent, to give 11 as a colourless oil (1.25 g; Yield 54\%). IR (NaCl): $v=3383,3030,2738,1918$, 1736, 1607, 1467, 1387, 1329, 1254, 1200, 1156, 1020, 968, 776, $667 \mathrm{~cm}^{-1} .{ }^{1} \mathrm{H}$ NMR $\left(\mathrm{CDCl}_{3}\right): \delta=-0.12\left(\mathrm{~s}, 3 \mathrm{H}, \mathrm{CH}_{3}\right),-0.04\left(\mathrm{~s}, 3 \mathrm{H}, \mathrm{CH}_{3}\right), 0.76\left(\mathrm{~s}, 9 \mathrm{H}, \mathrm{C}\left(\mathrm{CH}_{3}\right)_{3}\right), 1.84-1.90$

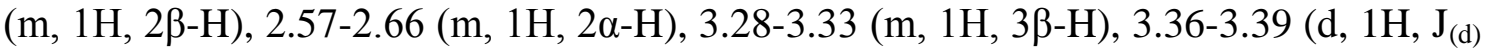
$=3.45 \mathrm{~Hz}$, exchangeable with $\left.\mathrm{D}_{2} \mathrm{O}\right), 3.88-3.89\left(\mathrm{~d}, 2 \mathrm{H}, \mathrm{J}_{(\mathrm{d})}=3.36 \mathrm{~Hz}, \mathrm{C}_{2} \mathrm{OSi}_{-}\right), 4.99-$ $5.05(\mathrm{~m}, 1 \mathrm{H}, 1 \beta-\mathrm{H}), 7.24-7.31(\mathrm{~m}, 3 \mathrm{H}, \mathrm{ArH}), 7.42-7.45(\mathrm{~m}, 1 \mathrm{H}, \mathrm{ArH}) .{ }^{13} \mathrm{C} \mathrm{NMR}$ $\left(\mathrm{CDCl}_{3}\right): \delta=-5.38\left(\mathrm{CH}_{3}\right),-5.24\left(\mathrm{CH}_{3}\right), 18.78(\mathrm{C}), 26.16\left(\mathrm{C}\left(\mathrm{CH}_{3}\right)_{3}\right), 39.81\left(\mathrm{CH}_{2}\right), 45.97$ $(\mathrm{CH}), 67.19\left(\mathrm{CH}_{2}\right), 74.98(\mathrm{CH}), 124.51,125.14,127.83$ and $128.82(\mathrm{CH}), 144.05(\mathrm{C})$, 146.69 (C). Anal. calcd. for $\mathrm{C}_{16} \mathrm{H}_{26} \mathrm{O}_{2} \mathrm{Si}$ : C, 69.01; H, 9.41. Found: C, 69.35; H, 9.19. ( \pm )-trans-3-[(tert-Butyldimethylsilyloxy)methyl]-1-indanyl benzoate, 12.

To a solution of $11(1.0 \mathrm{~g} ; 3.59 \mathrm{mmol})$, benzoic acid $(0.62 \mathrm{~g} ; 5.02 \mathrm{mmol})$ and triphenylphosphine (1.10 g; $3.95 \mathrm{mmol})$ in THF (40 mL) was added dropwise, under an argon atmosphere at $0^{\circ} \mathrm{C}$, a solution of DEAD $(1.56 \mathrm{~mL})$ in THF $(5 \mathrm{~mL})$. The mixture was stirred at $0^{\circ} \mathrm{C}$ for $1 \mathrm{~h}$ and at room temperature for $25 \mathrm{~h}$. Dichloromethane $(80 \mathrm{~mL})$ and saturated aqueous $\mathrm{NaHCO}_{3}(60 \mathrm{~mL})$ were added. The aqueous phase was extracted with dichloromethane $(3 \times 60 \mathrm{~mL})$ and the solvent was removed under reduced pressure to give a colourless solid, which was purified by column chromatography on silica gel (130 g), using hexane/AcOEt (60:1) as eluent, to give $\mathbf{1 2}$ as a colourless liquid (1.03 g; Yield 75\%). IR ( $\mathrm{NaCl}): v=3068,2857,1603,1462,1351,1175,1109,1024,941,838$, $758,712 \mathrm{~cm}^{-1} .{ }^{1} \mathrm{H}$ NMR $\left(\mathrm{CDCl}_{3}\right): \delta=0.01$ (s, 3H, $\left.\mathrm{CH}_{3} \mathrm{Si}-\right), 0.05\left(\mathrm{~s}, 3 \mathrm{H}, \mathrm{CH}_{3} \mathrm{Si}-\right), 0.89$ (s, 9H, C(CH3) $\left.)_{3}\right), 2.33-2.51(\mathrm{~m}, 2 \mathrm{H}, 2 \alpha-\mathrm{H}$ and $2 \beta-\mathrm{H}), 3.57-3.65(\mathrm{~m}, 1 \mathrm{H}, 3 \beta-\mathrm{H}), 3.70-$

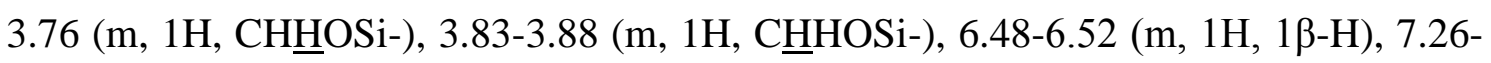
7.57 (m, 2H, ArH), 8.04-8.06 (m, 2H, ArH). ${ }^{13} \mathrm{C} \mathrm{NMR}\left(\mathrm{CDCl}_{3}\right): \delta=-0.51\left(\mathrm{CH}_{3}\right),-4.98$ $\left(\mathrm{CH}_{3}\right), 18.68(\mathrm{C}), 26.29\left(\mathrm{CH}_{3}\right), 36.90\left(\mathrm{CH}_{2}\right), 46.11(\mathrm{CH}), 67.23\left(\mathrm{CH}_{2}\right), 78.53(\mathrm{CH})$, 125.10, 126.02, 127.77, 128.68, 129.28, 130.09, 130.91 and $133.27(\mathrm{CH}), 142.15(\mathrm{C})$, 145.80 (C), 167.02 (C). Anal. calcd. for $\mathrm{C}_{23} \mathrm{H}_{30} \mathrm{O}_{3} \mathrm{Si}: \mathrm{C}, 72.21 ; \mathrm{H}, 7.90$. Found: C, $71.91 ; \mathrm{H}, 8.17$. 
(士)-trans-3-[(tert-Butyldimethylsilyloxy)methyl]-1-indanol, 13.

A solution of $12(0.5 \mathrm{~g} ; 1.307 \mathrm{mmol})$ and $\mathrm{MeONa}(0.5 \mathrm{~g} ; 1.43 \mathrm{mmol})$ in methanol (20 $\mathrm{mL}$ ) was stirred for $16 \mathrm{~h}$ under an argon atmosphere at room temperature. The solvent was removed under reduced pressure to give a colourless solid, which was purified by column chromatography on silica gel (45 g), using hexane/AcOEt (18:1) as eluent, to give 13 as a colourless oil $(0.280 \mathrm{~g}$; Yield 95\%). IR $(\mathrm{NaCl}): v=3345,3030,2930$, 2857, 1720, 1466, 1385, 1254, 1103, 939, 837, $775 \mathrm{~cm}^{-1} .{ }^{1} \mathrm{H}$ NMR $\left(\mathrm{CDCl}_{3}\right): \delta=-0.06$ (s, 3H, $\mathrm{CH}_{3}$ ), - 0.09 (s, 3H, $\left.\mathrm{CH}_{3}\right), 0.83\left(\mathrm{~s}, 9 \mathrm{H}, \mathrm{C}\left(\mathrm{CH}_{3}\right)_{3}\right), 2.02-2.10(\mathrm{~m}, 1 \mathrm{H}, 2 \beta-\mathrm{H}), 2.28-$

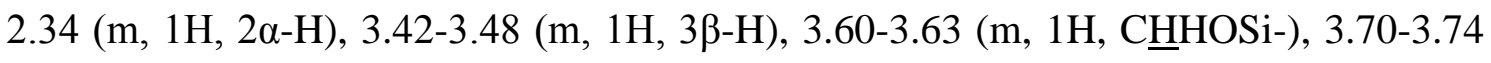

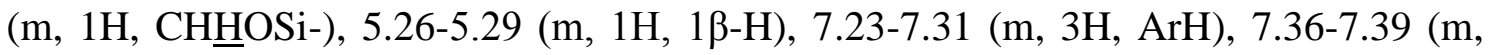
$1 \mathrm{H}, \mathrm{ArH}) .{ }^{13} \mathrm{C} \mathrm{NMR}\left(\mathrm{CDCl}_{3}\right): \delta=5.50\left(\mathrm{CH}_{3}\right), 18.24(\mathrm{C}), 25.84\left(\mathrm{CH}_{3}\right), 39.74\left(\mathrm{CH}_{2}\right)$, $45.39(\mathrm{CH}), 66.91\left(\mathrm{CH}_{2}\right), 75.45(\mathrm{CH}), 124.21,124.91,127.36$ and $128.28(\mathrm{CH}), 144.27$ (C), 145.49 (C). Anal. calcd. for $\mathrm{C}_{16} \mathrm{H}_{26} \mathrm{O}_{2} \mathrm{Si}$ : C, 69.01; H, 9.41. Found: C, 69.29; H, 9.21 .

( \pm )-cis-3-(6-Chloro-9H-purin-9-yl)-1-[(tert-butyldimethylsilyloxy)methyl]indan, 14. To a solution of $\mathbf{1 3}(0.280 \mathrm{~g} ; 1.006 \mathrm{mmol})$, triphenylphosphine $(0.300 \mathrm{~g} ; 1.107 \mathrm{mmol})$ and 6-chloropurine $(0.220 \mathrm{~g} ; 1.41 \mathrm{mmol})$ in THF $(20 \mathrm{~mL})$, under an argon atmosphere and at $0^{\circ} \mathrm{C}$, was added dropwise a solution of DEAD $(0.440 \mathrm{~mL} ; 1.107 \mathrm{mmol})$ in THF $(10 \mathrm{~mL})$. The mixture was stirred for $1 \mathrm{~h}$ at $0^{\circ} \mathrm{C}$ and for $39 \mathrm{~h}$ at room temperature. The solvent was removed under reduced pressure and the residue was purified by column chromatography on silica gel (50 g), using hexane/AcOEt (18:1) as eluent, to give $\mathbf{1 4}$ as a yellow oil (0.100 g; Yield 24\%). IR ( $\mathrm{NaCl})$ : v = 2928, 1562, 1391, 1254, 1066, 837, $776 \mathrm{~cm}^{-1} .{ }^{1} \mathrm{H}$ NMR $\left(\mathrm{CDCl}_{3}\right): \delta=0.0016-0.03\left(2 \mathrm{~s}, 6 \mathrm{H}, 2 \mathrm{CH}_{3}\right), 0.84\left(1 \mathrm{~s}, 9 \mathrm{H}, \mathrm{C}\left(\mathrm{CH}_{3}\right)_{3}\right)$, 2.11-2.21 (dt, $\left.1 \mathrm{H}, \mathrm{J}_{(\mathrm{t})}=13.65 \mathrm{~Hz}, \mathrm{~J}_{(\mathrm{d})}=7.36 \mathrm{~Hz}, 2 \beta-\mathrm{H}\right), 2.98-3.04\left(\mathrm{dt}, 1 \mathrm{H}, \mathrm{J}_{(\mathrm{t})}=13.64\right.$ $\left.\mathrm{Hz}, \mathrm{J}_{(\mathrm{d})}=8.41 \mathrm{~Hz}, 2 \alpha-\mathrm{H}\right), 3.46-3.54(\mathrm{~m}, 1 \mathrm{H}, 1 \beta-\mathrm{H}), 4.023-4.13\left(\mathrm{~m}, 2 \mathrm{H}, \mathrm{CH}_{2} \mathrm{OSi}-\right), 6.31-$ $6.34(\mathrm{~m} \mathrm{1H}, 3 \beta-\mathrm{H}), 7.01-7.04(\mathrm{~d}, 1 \mathrm{H}, \mathrm{J}=7.51 \mathrm{~Hz}, \operatorname{ArH}), 7.26-7.47$ (m, 3H, ArH), 8.00 $\left(\mathrm{s}, 1 \mathrm{H}, 8^{\prime}-\mathrm{H}\right), 8.79\left(\mathrm{~s}, 1 \mathrm{H}, 2^{\prime}-\mathrm{H}\right) .{ }^{13} \mathrm{C} \mathrm{NMR}\left(\mathrm{CDCl}_{3}\right): \delta=26.25\left(\mathrm{CH}_{3}\right), 37.45\left(\mathrm{CH}_{2}\right)$, $45.83(\mathrm{CH}), 58.69(\mathrm{CH}), 66.05\left(\mathrm{CH}_{2}\right), 124.62,125.41,128.44$ and $129.70(\mathrm{CH}), 132.14$ (C) 132.15 (C trans), $140.28(\mathrm{C}), 144.33(\mathrm{CH}), 144.95(\mathrm{C}), 151.46(\mathrm{C}), 152.32(\mathrm{CH})$, 152.47 (C). Anal. calcd. for $\mathrm{C}_{21} \mathrm{H}_{27} \mathrm{ClN}_{4} \mathrm{OSi}$ : C, 60.78; H, 6.56; N, 13.50. Found: C, $61.09 ; \mathrm{H}, 6.38 ; \mathrm{N}, 13.67$. 
(士)-cis-3-(6-Hydroxy-9H-purin-9-yl)-1-indanylmethanol, 15.

A solution of $14(0.060 \mathrm{~g} ; 0.145 \mathrm{mmol})$ in 1,4-dioxane $(15 \mathrm{~mL})$ and $0.25 \mathrm{~N} \mathrm{NaOH}(8$ $\mathrm{mL}$ ) was stirred for $4 \mathrm{~h}$ at room temperature. The solvent was removed under reduced pressure and successive coevaporations with toluene were carried out to remove any residual solvent. A colourless oil was obtained and this was purified by column chromatography on silica gel (12 g), using $\mathrm{CH}_{2} \mathrm{Cl}_{2} / \mathrm{MeOH}(30: 1)$ as eluent, to give 15 as a colourless solid $(0.030 \mathrm{~g}$; Yield $73 \%)$. M.p. $168-170^{\circ} \mathrm{C}$. IR $(\mathrm{KBr}): \mathrm{v}=3417,2923$, 1693, 1586, 1459, 1379, 1212, 1032, $650 \mathrm{~cm}^{-1} .{ }^{1} \mathrm{H}$ NMR $\left(\mathrm{CDCl}_{3}\right): \delta=2.21-2.31(\mathrm{dt}$, $\left.1 \mathrm{H}, \mathrm{J}_{(\mathrm{t})}=13.43 \mathrm{~Hz}, \mathrm{~J}_{(\mathrm{d})}=7.62 \mathrm{~Hz}, 2 \beta-\mathrm{H}\right), 2.93-3.03\left(\mathrm{dt}, 1 \mathrm{H}, \mathrm{J}_{(\mathrm{t})}=13.43 \mathrm{~Hz}, \mathrm{~J}_{(\mathrm{d})}=8.31\right.$ $\mathrm{Hz}, 2 \alpha-\mathrm{H}), 3.45-3.49(\mathrm{~m}, 1 \mathrm{H}, 1 \beta-\mathrm{H}), 3.84-3.98\left(\mathrm{~m}, 2 \mathrm{H}, \mathrm{C}_{2} \mathrm{O}\right), 6.16-6.21\left(\mathrm{t}, 1 \mathrm{H}, \mathrm{J}_{(\mathrm{t})}=\right.$ $8.01 \mathrm{~Hz}, 3 \beta-\mathrm{H}), 7.01-7.03\left(\mathrm{~d}, 1 \mathrm{H}, \mathrm{J}_{(\mathrm{d})}=7.58 \mathrm{~Hz}, \operatorname{ArH}\right), 7.23-7.28\left(\mathrm{t}, 1 \mathrm{H}, \mathrm{J}_{(\mathrm{t})}=7.42 \mathrm{~Hz}\right.$, $\operatorname{ArH}), 7.34-7.39\left(\mathrm{t}, 1 \mathrm{H}, \mathrm{J}_{(\mathrm{t})}=7.44 \mathrm{~Hz}, \operatorname{ArH}\right), 7.46-7.49(\mathrm{~m}, 1 \mathrm{H}, \operatorname{ArH}), 7.91\left(\mathrm{~s}, 1 \mathrm{H}, 2^{\prime} \mathrm{H}\right)$,

$8.05\left(\mathrm{~s}, 1 \mathrm{H}, 8^{\prime} \mathrm{H}\right) .{ }^{13} \mathrm{C} \mathrm{NMR}\left(\mathrm{CDCl}_{3}\right): \delta=37.99\left(\mathrm{CH}_{2}\right), 46.56(\mathrm{CH}), 59.77(\mathrm{CH}), 65.53$ $\left(\mathrm{CH}_{2}\right), 66.18\left(\mathrm{CH}_{2}\right), 125.11(\mathrm{CH}), 125.30(\mathrm{C}), 125.77,128.87$ and $130.11(\mathrm{CH}), 140.71$ (CH), $142.19(\mathrm{C}), 145.63(\mathrm{C}), 146.55(\mathrm{CH}), 150.45(\mathrm{C})$. Anal. calcd. for $\mathrm{C}_{15} \mathrm{H}_{14} \mathrm{~N}_{4} \mathrm{O}_{2}$ : C, 63.82; H, 5.00; N, 19.85. Found: C, 63.66; H, 5.24; N, 19.55.

( \pm )-cis-3-(6- $N$-Cyclopropylamino-9H-purin-9-yl)-1-[(tert-butyldimethylsilyloxy)methyl]indan, 16.

In a pressure reactor, previously purged with argon, was placed a solution of $14(0.100$ g; $0.241 \mathrm{mmol})$ and $N$-cyclopropylamine $(0.027 \mathrm{~mL} ; 0.265 \mathrm{mmol})$ in THF $(15 \mathrm{~mL})$ and the mixture was stirred for $150 \mathrm{~h}$ a $50^{\circ} \mathrm{C}$. The solvent was removed under reduced pressure to give a yellow oil, which was purified by column chromatography on silica gel (8 g), using $\mathrm{CHCl}_{3}$ /isopropanol (60:1) as eluent, to give $\mathbf{1 6}$ as a yellow oil (0.070 g; Yield 67\%). IR (NaCl): $v=3387,1732,1560,1350,1242,1066 \mathrm{~cm}^{-1} .{ }^{1} \mathrm{H}$ NMR $\left(\mathrm{CDCl}_{3}\right): \delta=-0.01\left(\mathrm{~s}, 3 \mathrm{H}, \mathrm{CH}_{3}\right), 0.03\left(\mathrm{~s}, 3 \mathrm{H}, \mathrm{CH}_{3}\right), 0.83\left(\mathrm{~s}, 9 \mathrm{H}, \mathrm{C}\left(\mathrm{CH}_{3}\right)_{3}\right), 1.03-1.05$ $\left(\mathrm{m}, 4 \mathrm{H}\right.$, cyclopropyl- $\left.\left(\mathrm{CH}_{2}\right)_{2}\right), 2.08-2.18\left(\mathrm{dt}, 1 \mathrm{H}, \mathrm{J}_{(\mathrm{t})}=13.71 \mathrm{~Hz}, \mathrm{~J}_{(\mathrm{d})}=7.10 \mathrm{~Hz}, 2 \beta-\mathrm{H}\right)$, 2.97-3.07 (dt, $\left.1 \mathrm{H}, \mathrm{J}_{(\mathrm{t})}=13.71 \mathrm{~Hz}, \mathrm{~J}_{(\mathrm{d})}=8.43 \mathrm{~Hz}, 2 \alpha-\mathrm{H}\right), 3.45-3.54(\mathrm{~m}, 3 \mathrm{H}, 1 \beta-\mathrm{H}+1 \alpha-\mathrm{H}$ + -CH-cyclopropyl), 3.87-3.92 (Part A of an ABM system, $1 \mathrm{H}, \mathrm{J}_{\mathrm{AB}}=11.13 \mathrm{~Hz}, \mathrm{~J}_{\mathrm{AM}}=$ $5.28 \mathrm{~Hz},-$ C $\underline{H} H O S i-)$, 3.92-3.97 (Part B of an ABM system, $1 \mathrm{H}, \mathrm{J}_{\mathrm{BA}}=11.13 \mathrm{~Hz}, \mathrm{~J}_{\mathrm{BM}}=$ $5.27 \mathrm{~Hz},-\mathrm{CH} \underline{H O S i}-), 6.18-6.23\left(\mathrm{t}, 1 \mathrm{H}, \mathrm{J}_{(\mathrm{t})}=7.62 \mathrm{~Hz}, 3 \beta-\mathrm{H}\right), 7.04-7.07\left(\mathrm{~d}, 1 \mathrm{H}, \mathrm{J}_{(\mathrm{d})}=\right.$ 7.56 Hz, ArH), 7.29-7.42 (m, 3H, ArH), 7.67 (s, 1H, 2'H), 7.82 (s, 1H, 8'H), 8.31 (b.s., $1 \mathrm{H}, \mathrm{NH}$, exchangeable with $\left.\mathrm{D}_{2} \mathrm{O}\right) .{ }^{13} \mathrm{C} \mathrm{NMR}\left(\mathrm{CDCl}_{3}\right): \delta=25.82\left(\mathrm{CH}_{2}\right), 26.09\left(\mathrm{CH}_{3}\right)$, 
$37.07\left(\mathrm{CH}_{2}\right), 45.45\left(\mathrm{CH}_{3}\right), 58.36\left(\mathrm{CH}_{2}\right), 65.59(\mathrm{CH}), 124.25,124.44,125.01$ and 125.34 (ArH), $128.06(\mathrm{CH}), 128.20$ (C), $129.44(\mathrm{CH}), 129.61$ (C), 137.37 (C), 154.35 (C). Anal. calcd. for $\mathrm{C}_{24} \mathrm{H}_{33} \mathrm{~N}_{5} \mathrm{OSi}$ : C, 66.17; H, 7.64; N, 16.08. Found: C, 65.81; H, 7.45; N, 16.38 .

\section{(士)-cis-3-(6-N-Cyclopropylamino-9H-purin-9-yl)-1-indanylmethanol, 17.}

To a solution of $16(0.06 \mathrm{~g}$; $0.147 \mathrm{mmol})$ in THF $(10 \mathrm{~mL})$ was added a mixture of $\mathrm{TFA} / \mathrm{H}_{2} \mathrm{O}(3: 1)(6 \mathrm{~mL})$ and the mixture was stirred for $21 \mathrm{~h}$ at room temperature. The solvent was removed under reduced pressure and several coevaporations with toluene were carried out to remove residual solvent. A yellow oil was obtained and this was purified by column chromatography on silica gel (5 g), using $\mathrm{CH}_{2} \mathrm{Cl}_{2} /$ isopropanol (30:1) as eluent, to give $\mathbf{1 7}$ as a colourless solid (0.020 g; Yield 42\%). $\mathrm{IR}(\mathrm{KBr})$ : $v=3394$, 1618, 1458, 1198, 1038, 785, $649 \mathrm{~cm}^{-1} .{ }^{1} \mathrm{H}$ NMR $\left(\mathrm{CDCl}_{3}\right): \delta=0.85-0.97(\mathrm{~m}, 4 \mathrm{H}$, cyclopropyl- $\left.\left(\mathrm{CH}_{2}\right)_{2}\right), 2.30-2.40\left(\mathrm{dt}, 1 \mathrm{H}, \mathrm{J}_{(\mathrm{t})}=13.94 \mathrm{~Hz}, \mathrm{~J}_{(\mathrm{d})}=7.00 \mathrm{~Hz}, 2 \beta-\mathrm{H}\right), 2.99-3.10$ $\left(\mathrm{dt}, 1 \mathrm{H}, \mathrm{J}_{(\mathrm{t})}=13.94 \mathrm{~Hz}, \mathrm{~J}_{(\mathrm{d})}=8.87 \mathrm{~Hz}, 2 \beta-\mathrm{H}\right), 3.14(\mathrm{~m}, 1 \mathrm{H}$, cyclopropyl-CH), 3.51-3.59 $\left(\mathrm{m}, 1 \mathrm{H}, 1 \beta-\mathrm{H}\right.$ ), 3.98-4.04 (part $\mathrm{A}$ of an $\mathrm{ABM}$ system, $1 \mathrm{H}, \mathrm{J}_{\mathrm{AB}}=10.90 \mathrm{~Hz}, \mathrm{~J}_{\mathrm{AM}}=4.03$ $\mathrm{Hz},-\mathrm{C} \underline{\mathrm{H} H O H}$ ), 4.06-4.11 (part B of an ABM system, $1 \mathrm{H}, \mathrm{J}_{\mathrm{BA}}=10.90 \mathrm{~Hz}, \mathrm{~J}_{\mathrm{BM}}=4.65$ $\mathrm{Hz},-\mathrm{CH} \underline{\mathrm{HOH}}), 6.12-6.17\left(\mathrm{t}, 1 \mathrm{H}, \mathrm{J}_{(\mathrm{t})}=7.85 \mathrm{~Hz}, 3 \beta-\mathrm{H}\right), 6.24-6.29\left(\mathrm{t}, 1 \mathrm{H}, \mathrm{J}_{(\mathrm{t})}=5.89 \mathrm{~Hz}\right.$, $3 \alpha-\mathrm{H}), 7.02-7.05\left(\mathrm{~d}, 1 \mathrm{H}, \mathrm{J}_{(\mathrm{d})}=7.60 \mathrm{~Hz}, \mathrm{ArH}\right), 7.22-7.31(\mathrm{~m}, 1 \mathrm{H}, \operatorname{ArH}), 7.36-7.47(\mathrm{~m}$, $2 \mathrm{H}, \mathrm{ArH}), 7.74\left(\mathrm{~s}, 1 \mathrm{H}, 8^{\prime}-\mathrm{H}\right), 8.39(\mathrm{~s}, 1 \mathrm{H}, 2 \mathrm{-}-\mathrm{H}) .{ }^{13} \mathrm{C} \mathrm{NMR}\left(\mathrm{CDCl}_{3}\right): \delta=7.51\left(\mathrm{CH}_{2}\right)$, $29.76(\mathrm{CH}), 36.08\left(\mathrm{CH}_{2}\right), 45.37(\mathrm{CH}), 58.48(\mathrm{CH}), 64.97\left(\mathrm{CH}_{2}\right), 119.96(\mathrm{C}), 124.62$, 125.07, 128.10 and $129.41(\mathrm{CH}), 138.67(\mathrm{C}), 139.38(\mathrm{C}), 140.90(\mathrm{CH}), 143.81(\mathrm{CH})$, 144.37 (C). Anal. calcd. for $\mathrm{C}_{18} \mathrm{H}_{19} \mathrm{~N}_{5} \mathrm{O}$ : C, 67.27; H, 5.96; N, 21.79. Found: C, 67.45; H, 6.19; N, 21.46.

\section{( \pm )-cis-5-Chloro-1-(3-hydroxymethyl-1-indanyl)-1,2,3,4-tetrahydropyrimidino-2,4-} dione, 19.

A solution of $\mathbf{1 8}^{16}$ (32 $\mathrm{mg}$; $0.124 \mathrm{mmol}$ ) and NCS (17.5 mg; $0.129 \mathrm{mmol}$ ) in DMF (10 $\mathrm{mL}$ ) was stirred, under an argon atmosphere, for $1 \mathrm{~h}$ at room temperature. The DMF was removed under reduced pressure with the aid of repeated coevaporations with toluene. The residue was purified by column chromatography on silica gel (16 g), using dichloromethane/methanol (40:1) as eluent, to give 19 as a colourless solid (15 mg; Yield 25\%). M.p. $248^{\circ} \mathrm{C}$ (decomposition). IR (KBr): $v=3546,3262,3036,1689,1454$, 1376, 1259, 1069, $766 \mathrm{~cm}^{-1} .{ }^{1} \mathrm{H}$ NMR (DMSO): $\delta=1.86-1.98\left(\mathrm{dt}, 1 \mathrm{H}, J_{(\mathrm{t})}=13.67 \mathrm{~Hz}\right.$, 
$\left.J_{(\mathrm{d})}=7.55 \mathrm{~Hz}, 2^{\prime} \beta-\mathrm{H}\right), 2.76-2.89\left(\mathrm{dt}, 1 \mathrm{H}, J_{(\mathrm{t})}=13.67 \mathrm{~Hz}, J_{(\mathrm{d})}=8.59 \mathrm{~Hz}, 2^{\prime} \alpha-\mathrm{H}\right), 3.30-$ $3.39\left(\mathrm{~m}, 1 \mathrm{H}, 3^{\prime} \beta-\mathrm{H}\right), 3.85-3.91$ (part A of an ABM system, $J_{\mathrm{AB}}=10.96 \mathrm{~Hz}, J_{\mathrm{AM}}=4.29$ $\mathrm{Hz}, \mathrm{C} \underline{H} H O$ ), 3.94-4.01 (part B of an ABM system, $J_{\mathrm{BA}}=10.96 \mathrm{~Hz}, J_{\mathrm{BM}}=4.79 \mathrm{~Hz}$, CHㅡㅁ), 4.65-5.01 (s, 1H, OH exchangeable with $\left.\mathrm{D}_{2} \mathrm{O}\right), 6.07-6.14\left(\mathrm{t}, 1 \mathrm{H}, J_{(\mathrm{t})}=7.99 \mathrm{~Hz}\right.$, 1' $\beta-\mathrm{H}), 7.13-7.16(\mathrm{~d}, 1 \mathrm{H}, J=7.21 \mathrm{~Hz}, \mathrm{ArH}), 7.28-7.46(\mathrm{~m}, 3 \mathrm{H}, \mathrm{ArH}), 7.58$ (s, 1H, 6-H), 11.65-12.09 (s, 1H, NH exchangeable with $\left.\mathrm{D}_{2} \mathrm{O}\right) .{ }^{13} \mathrm{C}$ NMR (DMSO): $\delta=34.75\left(\mathrm{CH}_{2}\right)$, $44.52(\mathrm{CH}), 59.02(\mathrm{C}), 63.57\left(\mathrm{CH}_{2}\right), 107.25(\mathrm{C}), 124.33,124.97,127.78$ and 128.90 (CH), $139.80(\mathrm{CH}), 140.99$ (C), 145.66 (C), 150.92 (C), 159.55 (C). Anal. calcd. for $\mathrm{C}_{14} \mathrm{H}_{13} \mathrm{ClN}_{2} \mathrm{O}_{3}: \mathrm{C}, 57.44 ; \mathrm{H}, 4.48 ; \mathrm{N}, 9.57$. Found: C, 57.67; H, 4.73; N, 9.69.

( \pm )-cis-5-Bromo-1-(3-hydroxymethyl-1-indanyl)-1,2,3,4-tetrahydropyrimidino-2,4dione, 20.

The same procedure as described in section $\mathbf{5 . 1 8}$ was used to prepare compound 20 from 18 by reaction with NBS. (Yield 73\%). M.p. $246^{\circ} \mathrm{C}$ (decomposition). IR (KBr): v $=3037,1858,1687,1502,1446,1326,1262,910,768 \mathrm{~cm}^{-1} .{ }^{1} \mathrm{H}$ NMR (DMSO): $\delta=$ $1.83-1.94\left(\mathrm{dt}, 1 \mathrm{H}, J_{(\mathrm{t})}=13.68 \mathrm{~Hz}, J_{(\mathrm{d})}=7.52 \mathrm{~Hz}, 2^{\prime} \beta-\mathrm{H}\right), 2.72-2.84\left(\mathrm{dt}, 1 \mathrm{H}, J_{(\mathrm{t})}=13.68\right.$ $\left.\mathrm{Hz}, J_{(\mathrm{d})}=8.60 \mathrm{~Hz}, 2^{\prime} \alpha-\mathrm{H}\right), 3.27-3.34\left(\mathrm{~m}, 1 \mathrm{H}, 3^{\prime} \beta-\mathrm{H}\right), 3.81-3.87$ (part A of an ABM system, $J_{\mathrm{AB}}=10.98 \mathrm{~Hz}, J_{\mathrm{AM}}=4.16 \mathrm{~Hz}, \mathrm{C} \underline{\mathrm{HHO}}$ ), 3.90-3.97 (part B of an ABM system, $\left.J_{\mathrm{BA}}=10.98 \mathrm{~Hz}, J_{\mathrm{BM}}=4.72 \mathrm{~Hz}, \mathrm{CH} \underline{\mathrm{HO}}\right), 6.03-6.10\left(\mathrm{t}, 1 \mathrm{H}, J_{(\mathrm{t})}=7.96 \mathrm{~Hz}, 1^{\prime} \beta-\mathrm{H}\right), 7.09-$ 7.12 (d, 1H, J = 7.45 Hz, ArH), 7.24-7.42 (m, 3H, ArH), 7.63 (s, 1H, 6-H), 11.90-12.03 (s, 1H, NH exchangeable with $\left.\mathrm{D}_{2} \mathrm{O}\right) .{ }^{13} \mathrm{C}$ NMR (DMSO): $\delta=34.74\left(\mathrm{CH}_{2}\right), 44.52(\mathrm{CH})$, $59.02\left(\mathrm{CH}_{2}\right), 63.51(\mathrm{CH}), 95.48(\mathrm{C}), 123.98,124.64,127.45$ and $128.57(\mathrm{CH}), 140.69$ (C), $141.88(\mathrm{CH}), 145.33(\mathrm{C}), 150.78(\mathrm{C}), 159.35$ (C). Anal. calcd. for $\mathrm{C}_{14} \mathrm{H}_{13} \mathrm{BrN}_{2} \mathrm{O}_{3}$ : C, 49.87; H, 3.89; N, 8.31. Found: C, 50.11; H, 3.71; N, 8.46.

( \pm )-cis-5-Iodo-1-(3-hydroxymethyl-1-indanyl)-1,2,3,4-tetrahydropyrimidino-2,4dione, 21.

A solution of 18 (32 mg; $0.124 \mathrm{mmol})$ and NIS (27 mg; $0.129 \mathrm{mmol})$ in acetic acid (10 $\mathrm{mL}$ ) was stirred, under an argon atmosphere, for $36 \mathrm{~h}$ at room temperature. The acetic acid was removed under reduced pressure and the residue was dissolved in $0.5 \mathrm{M} \mathrm{NaOH}$ and neutralised with $0.5 \mathrm{M} \mathrm{HCl}$. The material was concentrated under reduced pressure and the residue was purified by column chromatography on silica gel (11 g), using dichloromethane/methanol (25:1) as eluent, to give 21 as a colourless solid (25 mg; Yield $60 \%$ ). M.p. $225-227^{\circ} \mathrm{C}$. IR (KBr): $v=3505,1681,1492,1443,1327,1261,1025$, 
911, $756 \mathrm{~cm}^{-1} .{ }^{1} \mathrm{H}$ NMR (DMSO): $\delta=1.75-1.86\left(\mathrm{dt}, 1 \mathrm{H}, J_{(\mathrm{t})}=13.45 \mathrm{~Hz}, J_{(\mathrm{d})}=7.61 \mathrm{~Hz}\right.$, $\left.2^{\prime} \beta-\mathrm{H}\right), 2.54-2.66\left(\mathrm{dt}, 1 \mathrm{H}, J_{(\mathrm{t})}=13.45 \mathrm{~Hz}, J_{(\mathrm{d})}=8.63 \mathrm{~Hz}, 2^{\prime} \alpha-\mathrm{H}\right), 3.21-3.39\left(\mathrm{~m}, 1 \mathrm{H}, 3^{\prime} \beta-\right.$ H), 3.70 (b.s., $\left.2 \mathrm{H}, \underline{\mathrm{C}}_{2} \mathrm{OH}\right), 4.75$ (s, $1 \mathrm{H}, \mathrm{OH}$ exchangeable with $\left.\mathrm{D}_{2} \mathrm{O}\right), 5.87-5.93(\mathrm{t}, 1 \mathrm{H}$, $\left.J_{(\mathrm{t})}=8.07 \mathrm{~Hz}, 1^{\prime} \beta-\mathrm{H}\right), 7.06-7.09(\mathrm{~d}, 1 \mathrm{H}, J=7.25 \mathrm{~Hz}, \operatorname{ArH}), 7.17-7.29(\mathrm{~m}, 2 \mathrm{H}, \operatorname{ArH})$, 7.34-7.37 (d, 1H, J=7.25 Hz, ArH), 7.61 (s, 1H, 6-H), 10.80 (s, 1H, NH exchangeable with $\left.\mathrm{D}_{2} \mathrm{O}\right) .{ }^{13} \mathrm{C}$ NMR (DMSO): $\delta=35.08\left(\mathrm{CH}_{2}\right), 44.87(\mathrm{CH}), 59.21(\mathrm{CH}), 63.79\left(\mathrm{CH}_{2}\right)$, $69.49(\mathrm{C}), 124.20,124.97,127.75$ and $128.85(\mathrm{CH}), 141.09(\mathrm{C}), 145.63(\mathrm{C}), 146.82$ $(\mathrm{CH}), 151.43$ (C), 160.98 (C). Anal. calcd. for $\mathrm{C}_{14} \mathrm{H}_{13} \mathrm{IN}_{2} \mathrm{O}_{3}$ : C, 43.77; H, 3.41; N, 7.29. Found: C, 44.01; H, 3.59; N, 7.13.

\section{Acknowledgements}

The authors thank the Xunta de Galicia for financial support of this work under projects PGIDT05PXIB20301PR and 07CSA008203PR.

\section{References and notes}

(1) Part of this work was presented at the XIV Congreso Nacional of The Sociedad Española de Química Terapéutica, Bilbao: Spain, September 2005.

(2) For recent reviews of the literature on carbanucleosides: (a) Rodríguez, J. B.; Comin, M. J. Mini-Rev. Med. Chem. 2003, 3, 95. (b) Ichikawa, E.; Kato, K. Curr. Top. Med. Chem. 2001, 8, 385. (c) Zhu, X.-F. Nucleosides, Nucleotides and Nucleic Acids 2000, 19, 651. (d) Ferrero, M.; Gotor, V. Chem. Rev. 2000, 100, 4319. (e) Agrofoglio, L.; Challand, S. R. Acyclic, Carbocyclic and L-Nucleosides; Kluwer Academic: Dordrecht, The Netherlands, 1998.

(3) (a) Roberts, S.; Biggadike, K.; Borthwick, A. D.; Kirk, B. Topics in Medicinal Chemistry; Leeming, P. R. Ed.; Royal Society of Chemistry: London, 1988. (b) Marquez, V. E.; Lim, M. Med. Res. Rev. 1986, 6, 1. (c) Saunders, J.; Cameron, J. M. Med. Res. Rev. 1995, 15, 497.

(4) (a) Vince, R.; Hua, M.; Brownell, J.; Daluge, S.; Lee, F.; Shannon, W. M.; Lavelle, G. C.; Qualls, J.; Weislow, O. S. et al. Biochem. Biophys. Res. Comm. 1988, 156, 1046. (b) Vince, R.; Hua, M. J. Med. Chem. 1990, 33, 17. (c) Vince, R.; Peterson, M. L.; Lackey, J. W.; Mook, R. A.; Partridge, J. J. PCT Int. Appl. 1991, WO 9115490, $50 \mathrm{pp}$. 
(5) (a) Daluge, S. M.; Good, S. S.; Faleto, M. B.; Miller, W. H.; St Clair, M. H.; Boone, L. R.; Tisdale, M.; Parry, N. R.; Reardon, J. E.; Dornsife, R. E.; Averett, D. R.; Krenitsky, T. A. Antimicrob. Agents Chemother. 1997, 41, 1082. (b) Crimmins, M. T.; King, B. W. J. Org. Chem. 1996, 61, 4192. (c) Foster, R. H.; Faulds, D. Drugs 1998, 55, 729.

(6) (a) Fernández, F.; García-Mera, X.; Morales, M.; Rodríguez-Borges, J. E.; De Clercq, E. Synthesis 2002, 1084. (b) Yao, S.-W.; López, V. H. C.; Fernández, F.; García-Mera, X.; Morales, M.; Rodríguez-Borges, J. E.; Cordeiro, M. N. D. S. Bioorg. Med. Chem. 2003, 11, 4999.

(7) (a) Fernández, F.; García-Mera, X.; Morales, M.; Vilariño, L.; Caamaño, O.; De Clercq, E. Tetrahedron 2004, 60, 9245. (b) Fernández, F.; García-Mera, X.; López, C.; Morales, M.; Rodríguez-Borges, J. E. Synthesis 2005, 3549.

(8) Thomas, S.; McDowall, J. E.; Cheah, V.; Bye, A.; Segal, M. B. "The entry of Abacavir into the guinea-pig brain: Comparison with other reverse transcriptase inhibitors", $12^{\text {th }}$ World AIDS Conference, 1998, Geneva.

(9) a) Cheson, B. D. Hematol. Cell. Ther. (Suppl. 2) 1996, 38, 109. (b) Bergmann, L. Leukemia (Suppl. 2) 1997, 11, 29. (b) Hocek, M.; Hol, A.; Votruba, I.; Dvoráková, H. J. Med. Chem. 2000, 43, 1817.

(10) Grunewald, G. L.; Sall, D. J.; Monn, J. A. J. Med. Chem. 1988, 31, 433.

(11) Fernández, F.; García-Mera, X.; Rodríguez-Borges, J. E. Tetrahedron: Asymmetry 2001, 12, 365 .

(12) (a) Mitsunobu, O. Synthesis 1981, 1. (b) Hughes, D. L. Org. React. 1992, 42, 335.

(c) Lawrence, S. PharmaChem 2002, 1, 12. (d) But, T. Y. S.; Toy, P. H. Chem. Asian J. 2007, 2, 1340.

(13) (a) Hocek, M. Eur. J. Org. Chem. 2003, 245. (b) Havelková, M.; Dvorák, D., Hocek, M. Synthesis 2001, 1704. (c) Havelková, M.; Hocek, M.; Cesnek, M; Dvorák, D., Synlett 1999, 1145.

(14) (a) Hocek, M. Eur. J. Org. Chem. 2003, 245. (b) Hocek, H.; Hockova, D.; Stambasky, J. Collect. Czech. Chem. Commun. 2003, 68, 837. (c) Hocek, H.; Holy, A.; Votruba, I.; Dvorakova, H. J. Med. Chem. 2000, 43, 1817. (d) Havelková, M.; Hocek, M.; Cesnek, M.; Dvorák, D. Synlett 1999, 1145.

(15) Corey, E. J.; Venkateswarlu, A. J. Am. Chem. Soc. 1972, 94, 6190. 
(16) Fernández, F.; García-Mera, X.; Morales, M.; Rodríguez-Borges, J. E. Synthesis 2001, 2, 239.

(17) (a) Sako, M.; Saito, T.; Kameyama, K.; Hirota, K.; Maki, Y. Synthesis 1987, 829.

(b) Srivastavam, P. C.; Nagpal, K. L. Experientia 1970, 26, 220.

(18) De Clercq, E. In Vivo and Ex Vivo Text Systems to Rationalize Drug Design and Delivery; Cromelin, D.; Couvreur, P.; Duchene, D., Eds.; Editions de Santé: Paris, 1994. 